\title{
REPENSANDO A RELAÇÃO ENTRE ESTADO, DIREITO E DESENVOLVIMENTO: OS LIMITES DO PARADIGMA RULE OF $L A W$ E A RELEVÂNCIA DAS ALTERNATIVAS INSTITUCIONAIS
}

\author{
Mario Gomes Schapiro
}

RETHINKING THE RELATION BETWEEN STATE,

LAW AND DEVELOPMENT

\section{RESUMO}

ASSUMINDO A PRIMAZIA DA ABORDAGEM INSTITUCIONALISTA NA AGENDA CONTEMPORÂNEA DO DESENVOLVIMENTO, ESTE ARTIGO PROCURARÁ DISCUTIR ALGUNS DE SEUS LIMITES, DESCRITIVOS E NORMATIVOS, NO QUE TANGE, EM ESPECIAL, AO SISTEMA FINANCEIRO. PARTICULARMENTE, PROCURAR-SE-Á SUgERIR QUE OS PROGRAMAS DE DIFUSÃo DO RULE OF LAW TÊM SE CONSTITUÍdO EM UM PARADIGMA ESTREITO DO PAPEL EXERCIDO PELO DIREITO, SEGUNDO A QUAL CABE AO AMBIENTE JURÍDICO CUMPRIR, APENAS E TÃO SOMENTE, A FUNČ̃O DE GARANTIDOR DOS INTERESSES DE INVESTIDORES PRIVADOS, ENTENDIDOS COMO ATORES CENTRAIS DE UM MODELO DE FINANCIAMENTO BASEADO EM TRANSACÕES DE MERCADO. 0 TEXTO SUgERE QUE O PARADIGMA RULE OF LAW, COMO ESTRATÉGIA DE PROMOÇÃO DO DESENVOLVIMENTO, TEM DIFICULDADE EM LIDAR COM A EXISTÊNCIA DE ALTERNATIVAS INSTITUCIONAIS DE ORGANIZAÇÃO ECONÔMICA E FINANCEIRA, PARA ALÉM DE UM MODELO DE MERCADO BASEAdO EM ATORES ATOMIZADOS E CARENTES DE SEgURANÇA JURÍDICA. UM EXEMPLO DISSO, QUE ESCAPA DO INSTRUMENTAL TRADICIONAL, É O MODELO BRASILEIRO DE FINANCIAMENTO, QUE, APESAR DE TER VIVENCIADO INÚMERAS REFORMAS INSTITUCIONAIS, DEDICADAS A ELEVAR O NIVEEL DE PROTEÇÃO DE INVESTIDORES, AINDA CONCENTRA EM UM BANCO DE DESENVOLVIMENTO - O BNDES GRANDE PARTE DO FINANCIAMENTO DE LONGO PRAZO DO PAÍS. O ARTIGO ASSUME, PORTANTO, QUE, SIM, O DIREITO E AS INSTITUIÇÕES, DE FATO, IMPORTAM PARA O DESENVOLVIMENTO, MAS HÁ UMA VARIEDADE DE POSSIBILIDADES E FUNÇŌES A SEREM EXERCIDAS PELOS ARRANJOS INSTITUCIONAIS E FERRAMENTAS JURIIDICAS - MUITO ALÉM DO QUE SUPÕEM OS PROgRamas DE RULE of LAW. UMA BEM SUCEDIDA ORGANIZAÇÃO INSTITUCIONAL BASEADA EM UM BANCO DE DESENVOLVIMENTO É UM EXEMPLO DISSO.

\section{PALAVRAS-CHAVE}

ALTERNATIVAS INSTITUCIONAIS; BANCO DE DESENVOLVIMENTO; RULE OF LAW; BNDES; DIREITO E DESENVOLVIMENTO: FINANCIAMENTO DO DESENVOLVIMENTO.

\section{ABSTRACT}

TAKEN THE PREVALENCE OF INSTITUTIONALIST AND RULE OF LAW APPROACH IN THE CONTEMPORARY DEBATE ON ECONOMIC DEVELOPMENT, THIS PAPER INTENDS TO DISCUSS SOME THEORETICAL LIMITS OF THIS LITERATURE, EITHER POSITIVE OR NORMATIVE, MAINLY IN ITS APPLICATION TO DISCUSSIONS RELATED TO THE FINANCIAL SECTOR. THIS ARTICLE CLAIMS THAT THE SPURRING OF DEVELOPMENT BASED ON RULE OF LAW PROGRAMS USUALLY ASSUMES A VERY LIMITED VIEW OF THE ROLES PLAYED BY THE LAW. ACCORDING TO THE PREVAILING VIEW, THE ROLE PLAYED BY INSTITUTIONS IN ECONOMIC DEVELOPMENT IS RESTRICTED TO PROVIDING LEGAL PROTECTION FOR PRIVATE INVESTORS, WHO ARE ASSUMED TO BE THE CENTRAL ACTORS OF THE FINANCIAL SYSTEM. THIS PAPER, HOWEVER, TAKES A DIFFERENT PATH AND TRIES TO ARGUE THAT THERE ARE DIFFERENT INSTITUTIONAL ALTERNATIVES OF ECONOMIC ORGANIZATION, WHICH GOES BEYOND AN ARRANGEMENT BASED ON CAPITAL MARKET AND ATOMIZED SHAREHOLDERS. AN EXAMPLE OF THAT IS THE BRAZILIAN FINANCIAL SYSTEM: IN SPITE OF RECENT RULE OF LAW TYPE OF REFORMS IT IS STILL DEPENDENT OF A DEVELOPMENTAL BANK - BNDES. AS A CONCLUSION, THE ARTICLE SUSTAINS THAT INDEED LAW AND INSTITUTIONS MATTER FOR DEVELOPMENT, BUT THERE ARE A VARIETY OF POSSIBLE INSTITUTIONAL ARRANGEMENTS AND ALSO SEVERAL ROLES AND FUNCTIONS TO BE PLAYED BY LEGAL TOOLS, A LOT BROADER THAN IT IS SUPPOSED BY RULE OF LAW DEVELOPMENT PROGRAMS. A SUCCESSFUL INSTITUTIONAL ORGANIZATION BASED ON A DEVELOPMENT BANK IS AN EXAMPLE OF THAT.

\section{KEYWORDS}

INSTITUTIONAL ALTERNATIVES; DEVELOPMENT BANK; RULE OF LAW; BNDES; LAW AND DEVELOPMENT; DEVELOPMENT FINANCING. 


\section{INTRODUÇÃO}

O tema do desenvolvimento, após um período de ostracismo acadêmico e político, voltou recentemente a despertar o interesse de pesquisadores e formuladores de política pública. O retorno desta agenda tem como particularidade o relevo atribuído ao ambiente jurídico-institucional, no âmbito tanto das agências multilaterais de fomento, como dos governos nacionais. Desde meados da década de 1990, sob a rubrica de Rule of Law, têm se difundido, nos mais diversos países em desenvolvimento, programas de qualificação institucional, voltados a um universo variado de propósitos, que inclui desde a reforma do Poder Judiciário até a incorporação de novos códigos legislativos, passando ainda pela promoção de novas regulações no ambiente financeiro e pela adoção de boas práticas de governança corporativa. $\mathrm{O}$ traço comum dessa agenda, cujos desdobramentos podem ser identificados em países tão diferentes como os latino-americanos e os da África Subsaariana, é a confiança na promoção do desenvolvimento a partir da promoção de boas regras do jogo, capazes de amparar um ambiente econômico estável e seguro para as transações privadas.

Em certa medida, este renascimento parece recuperar o roteiro de análises e proposições que ficou conhecido como Law \& Development, um campo de trabalho que já foi bastante frequentado por sociólogos do direito e policy makers, há não mais que quarenta anos. Ao longo da década de 1960 e no início da de 1970, estudos realizados por acadêmicos e formuladores de política norte-americanos e europeus procuravam identificar os atributos jurídico-institucionais que conformavam o funcionamento de mercados e sociedades de países periféricos, dedicando-se, ainda, a apresentar propostas de reformas institucionais, baseadas na percepção de que parte do subdesenvolvimento dessas nações se deveria justamente aos limites apresentados por este panorama. A concepção prevalecente de tais trabalhos costumava apontar que a falta de capacidade em oferecer uma resposta satisfatória ao ambiente de negócios, causada pela inadequação dos estatutos regulatórios e também pela carência de formação dos operadores do direito, seria uma importante lacuna institucional, a qual obstaculizaria o processo de desenvolvimento social e econômico destas nações (TRUBEK, 1972, pp. 2-10).

A retomada desse legado, que de algum modo tem embalado o viés dos novos estudos de desenvolvimento, traz consigo, no entanto, alguns vícios e equívocos, analíticos e propositivos, presentes desde as primeiras abordagens dedicadas às relações entre o ambiente jurídico-institucional e o desenvolvimento. Este é o caso da dificuldade demonstrada em compreender as especificidades institucionais dos países retardatários. Desde os primeiros trabalhos nesta chave, pode-se reconhecer um viés de análise que costuma identificar as singularidades institucionais como se fossem desvios, ou equívocos, para cuja solução se tem recomendado, habitualmente, a adoção de um "pacote de instituições corretas", transplantáveis de ambientes dotados de 
um bem sucedido processo de desenvolvimento. Uma estratégia que, todavia, nem sempre tem alcançado os resultados esperados, seja pela resistência política encontrada nos países para a realização das reformas institucionais, seja pela carência de efetividade de tais medidas - em muitos casos -, inconsistentes com a trajetória histórica vivenciada pelos arranjos nacionais.

Assumindo a primazia da abordagem institucionalista na agenda contemporânea do desenvolvimento, este artigo procurará discutir alguns desses limites, descritivos e normativos, no que tange, em especial, ao sistema financeiro. Particularmente, procurar-se-á sugerir que os programas de difusão do Rule of Law têm se constituído em um paradigma estreito, baseando-se em uma visão monocórdica do papel exercido pelo direito, segundo a qual cabe ao ambiente jurídico cumprir a função, apenas e tão somente, de garantidor dos interesses de investidores privados, entendidos como atores centrais de um modelo de financiamento baseado em transações de mercado. O argumento central do texto sugere, portanto, que o paradigma Rule of Law, como estratégia de promoção do desenvolvimento, tem dificuldade em lidar com a existência de alternativas institucionais de organização econômica e financeira, para além de um modelo de mercado baseado em atores atomizados e carentes de segurança jurídica.

Desde já, é conveniente observar, entretanto, que esta análise crítica não desdenha da relevância do Estado de Direito, entendido como um arranjo moderno de limitação do arbítrio, de racionalização do poder e de preservação dos espaços de autonomia individual. Sucede, todavia, que, para além do sentido convencionalmente estipulado pelo pensamento político, a expressão Rule of Law tem sido utilizada como um slogan dos programas de desenvolvimento, conotando um tipo característico de desenho institucional associado a uma estratégia específica de promoção das economias subdesenvolvidas. É a esse aspecto que se volta este artigo.

Sendo assim, uma vez apresentados os limites dessa nova alquimia, este trabalho procurará reforçar a relevância de se considerar a relação existente entre os arranjos jurídico-institucionais e os respectivos contextos locais. Dessa maneira, será possível compreender o modelo brasileiro de financiamento, que, apesar de ter vivenciado inúmeras reformas institucionais, dedicadas a elevar o nível de proteção de investidores, ainda concentra em um banco de desenvolvimento - o BNDES grande parte do financiamento de longo prazo do país. O artigo assume, portanto, que, sim, o direito e as instituições de fato importam para o desenvolvimento, mas há uma variedade de possibilidades e funções a serem exercidas pelos arranjos institucionais e pelas ferramentas jurídicas - muito além do que supõem os programas de Rule of Law.

Para tanto, este trabalho está dividido em quatro partes. A parte 1 apresenta um panorama sintético da noção de Rule of Law tal como tem sido concebida e empregada pelas diversas propostas de reforma institucional realizadas pelos países em 
desenvolvimento nos últimos anos. A parte 2 sintetiza o sentido que tem sido emprestado ao Rule of Law no campo financeiro. A parte 3 se volta para uma análise do caso brasileiro, cujo modelo de financiamento corporativo tem contado, de modo significativo, com a participação direta do Estado - um dado curioso, que arrefece as expectativas e os prognósticos dos reformadores institucionais, os quais há algum tempo dedicam-se a promover o desenvolvimento financeiro do país por meio do "transplante das instituições corretas". A partir disso, a parte 4 procura discutir os limites do paradigma hegemônico (Rule of Law), bem como sugerir caminhos para uma abordagem alternativa, capaz de levar em conta os encadeamentos institucionais locais. Por fim, apresenta-se uma conclusão.

\section{O PARAdigma RULE OF LAW NO DESENVOLVIMENTO ECONÔMICO: TRANSAÇÕES PRIVADAS, GARANTIA JURÍdICA E RETRAÇÃO DO ESTADO}

A partir da década de 1990, a produção intelectual e a intervenção dos governos nacionais e das agências multilaterais passaram a ter no ambiente institucional um objeto de particular interesse. De um lado, pesquisadores começaram a tematizar, com mais frequência, a relevância do entorno institucional para a promoção das transações privadas em mercados, assumindo, ainda, a sua importância para o conjunto das economias e para as expectativas de crescimento econômico. De outro, agências internacionais inauguraram uma terceira fase em sua agenda de ação. Após terem amparado obras de infraestrutura e os programas públicos de investimento em países subdesenvolvidos, e, em seguida, terem priorizado o ajuste macroeconômico dos países cujos programas de desenvolvimento enfrentavam sinais de esgotamento (getting the prices right), o alvo da intervenção dessas entidades passou a ser o aprimoramento institucional das nações mais pobres (getting the institutions right) (TRUBEK, 2006, p. 81). Desde então, só o Banco Mundial reportou um dispêndio de cerca de US\$ 3 bilhões e uma participação ativa em 330 programas desta natureza (TRUBEK, 2006, p. 74). É bastante expressiva dessa inversão de prioridades a comparação apresentada por Robert Danino, então membro do staff diretor do Banco Mundial: ${ }^{2}$ há cerca de 30 anos, 58\% dos dispêndios do Banco eram alocados em projetos de infraestrutura, ao passo que, atualmente, essa rubrica responde por apenas $22 \%$ dos investimentos, enquanto os programas de qualificação institucional passaram a representar 52\% dos desembolsos do Banco.

Este entendimento em torno do ambiente institucional e da sua relevância para a promoção dos mercados tem consolidado um novo paradigma no campo da economia política do desenvolvimento - a noção de Rule of Law, um conjunto definido de concepções econômicas, interpretações jurídicas e estratégias políticas para a promoção do crescimento e da modernização econômica das nações (TRUBEK; SANTOS, 2006). No caso da estratégia Rule of Law, esta convergência entre ideias 
econômicas, noção de direito e estratégia política está associada a um determinado modelo de desenvolvimento econômico, que é baseado em transações privadas, mediadas pelas garantias jurídicas de proteção à propriedade privada e aos termos contratuais, e, ainda, é vinculado a um viés definido de políticas públicas, em que prevalece uma relação Estado-economia comprometida com a preservação dos mercados como espaços de alocação de recursos.

No âmbito das ideias econômicas, a concepção prevalecente que informa esse paradigma provém de uma apropriação dos estudos da Nova Economia Institucional (NEI), escola oriunda de uma revisão interna dos cânones da teoria econômica de matriz neoclássica, que introduziu as instituições como uma variável da análise econômica. Em relação ao mainstream neoclássico, os estudos de autores como Ronald Coase ou Oliver Williamson têm sugerido que, no mundo real, as trocas entre os agentes não são necessariamente instantâneas e perfeitas, e tampouco estes atores detêm uma racionalidade ilimitada. Diferentemente, os trabalhos da NEI têm procurado mostrar que nas transações econômicas não só ocorrem fricções (como os custos de transação), como a racionalidade dos agentes é limitada - a sua capacidade de decisão não é plena. Em razão disso, esses autores introduzem as instituições em suas análises, argumentando que as relações econômicas são reguladas por aparatos de coordenação, como a propriedade e o contrato. Na ausência destes, dada a incerteza, os custos de negociação e a limitação da racionalidade, os negócios podem não se consumar. Este é o caso, por exemplo, de uma troca envolvendo produtos específicos e de entrega futura: trata-se de um tipo de transação que envolve um bem singular e traz consigo um componente de imprevisibilidade, de tal modo que a sua viabilização pressupõe a mediação de um contrato de longo prazo, pois do contrário o custo de transação entre os agentes poderia ser muito significativo. Apesar de ser essa uma constatação trivial para um estudante de direito, não o era para um economista neoclássico, cujos modelos não internalizavam os elementos institucionais - a coordenação entre os agentes era, conceitualmente, uma responsabilidade do sistema de preços.

A partir da internalização das instituições como variáveis de análise, alguns estudos de viés neoinstitucionalista têm procurado ampliar o plano de observação, voltando-se a investigar a relação entre o desempenho econômico dos países e a qualidade dos respectivos ambientes institucionais. Entre estas pesquisas, é particularmente relevante o trabalho de Douglass North, notadamente o seu livro Institutions, Institutional Change and Economic Performance (1990). Partindo do pressuposto de que o ambiente institucional conforma a atuação dos agentes individuais, North argumenta que a razão do maior ou menor desenvolvimento relativo de alguns países deve-se à adoção histórica de uma estrutura de coordenação mais ou menos favorável à constituição de um ambiente impessoal, seguro e previsível para as trocas em mercado. É por esta razão, argumenta, que o nível de desenvolvimento da 
Inglaterra, onde teriam se desenvolvido regras de propriedade e contrato mais favoráveis às transações privadas, é superior ao da Espanha, que teria padecido de um ambiente institucional desfavorável (NORTH, 1990, pp. 113-117). O trabalho de North, enfim, não só tem reforçado o campo da NEI, ao projetar o papel das instituições no funcionamento dos mercados, como, principalmente, tem permitido a sua associação com a economia do desenvolvimento, ao sugerir que as experiências bemsucedidas resultam, entre outros, dos incentivos institucionais e da efetividade (enforcement) de sua aplicação.

A influência deste referencial de análise é bastante significativa e tem balizado diversos trabalhos dedicados às relações entre o ambiente institucional e o desenvolvimento econômico. Exemplos disso são as produções recentes de pesquisadores importantes, como Kenneth Dam (2006), Peter Evans (2005), Hernando De Soto (2000) e Adam Przeworski (2004), entre tantos outros, que partem dessa matriz institucional para a condução de suas investigações. Muito embora figurem entre esses alguns autores heterodoxos, como Evans e Przeworski, todos eles reconhecem a relevância da NEI e de North na literatura contemporânea sobre desenvolvimento e partem desse referencial para a realização de suas análises.

Apesar de trabalhos como o de North não apresentarem necessariamente argumentos normativos ou implicações de política, há uma conexão entre as abordagens da Nova Economia Institucional e o entusiasmo dos policy makers com estratégias de desenvolvimento baseadas na difusão de "instituições corretas" e "boas práticas de governança”. Isso porque, apesar de introduzir as instituições em um debate antes exclusivamente individualista, a Nova Economia Institucional mantém, ainda, célebres pressupostos do mainstream econômico, tais como: (i) o individualismo metodológico e (ii) a primazia do mercado. Assim como na herança neoclássica, no âmbito da NEI a ordem natural é a ordem de mercado, de modo que as instituições são concebidas em função da necessidade de seu funcionamento (CHANG; EVANS, 2005). Isso significa que as instituições, embora tenham sido incorporadas nos referenciais de análise, são compreendidas como aparatos reguladores externos, e não como elementos constitutivos (embedded) dos mercados (GRANOVETTER, 1985). Comportam, portanto, operações de engenharia social. ${ }^{3}$

No limite, a compreensão subsocializada das instituições tem dado sustentação conceitual a programas de desenvolvimento baseados na promoção de reformas institucionais, que são implementadas com o propósito de fortalecer a estrutura de garantias e incentivos disponíveis, para assim estimular a atuação dos agentes econômicos em mercado. Partindo da constatação de que o ambiente jurídico-institucional importa, mas tratando-o como uma variável externa à dinâmica social, os formuladores de política pública têm se voltado a modular as regras do jogo, com a finalidade de garantirem uma melhor arena para os jogadores econômicos. Valem-se para tanto, entre outros, do expediente dos "transplantes institucionais", dedicados a incorporar 
no ambiente jurídico-institucional de países em desenvolvimento regras e práticas bem-sucedidas em países desenvolvidos. ${ }^{4}$

Ao lado da prevalência da NEI, o lastro comum dos trabalhos e das políticas recentes sobre desenvolvimento é uma determinada concepção de direito, constituída a partir de uma apropriação daquilo que Milhaupt e Pistor (2008) identificam como um "legado weberiano" (p. 6). A noção de direito subjacente ao paradigma Rule of Law é a de um veículo promotor de garantia, previsibilidade e calculabilidade para as transações privadas. A existência de regras claras, a proteção adequada da propriedade privada, a certeza do cumprimento dos ajustes contratuais e a confiança no funcionamento célere e independente do Poder Judiciário passaram a ser consideradas como os itens necessários a serem atendidos pelos atributos jurídico-institucionais. Seriam estas, enfim, algumas das mais importantes variáveis para um bem-sucedido processo de desenvolvimento. A seguinte passagem de Milhaupt e Pistor (2008), descrevendo o senso predominante acerca da relação entre direito e desenvolvimento, indica que o emprego dado à noção de Rule of Law é bastante estreito e instrumental, sendo a noção vinculada à preservação (não distorção) dos espaços privados de transação econômica:

According to the prevailing view, law fosters economic activity (exclusively) by protecting property rights. A legal system that clearly allocates and protects property rights (a rule of law) precedes economic development and is a precondition to economic success. Once such a system is in place, it constitutes a fixed and politically neutral institutional endowment - an unchanging foundation for economic activity. The formal characteristics of legal system - in particular, whether they adhere to common law or civil law - determine how well they provide protection of property rights (especially investors' rights). The quality of property rights protections, in turn, determines economic outcomes. (p. 4)

No âmbito dessas análises e proposições, tem-se conferido uma dupla tarefa para a regulação jurídica: de um lado supõe-se que caiba às regras jurídicas a constituição de espaços seguros para as transações entre os agentes, e, de outro, que essas regras possam proteger os particulares da atuação discricionária do Estado (DAM, 2006, p. 15). Trata-se, pois, de uma concepção sobre a função do direito a qual é coerente com o postulado econômico da NEI, subjacente a este paradigma. Na medida em que as expectativas de crescimento econômico e sucesso das nações são depositadas no funcionamento adequado dos mercados, tomados como espaços necessários e suficientes de alocação dos recursos sociais, o papel esperado do direito é que este seja capaz de promover a segurança jurídica, o que envolve, em última análise, a garantia de estabilidade nas relações entre particulares.

Em consonância com tal perspectiva de desenvolvimento, pode-se constatar, nessa agenda, uma primazia do direito privado sobre o direito público (KENNEDY, 
2006, pp. 138-139). Diferentemente do contexto desenvolvimentista, entre as décadas de 1960 e 1970, em que os dispositivos de direito público dedicados a conceber o desenho do aparato institucional e encarregados de uma regulação ativa e vertical do ambiente econômico tinham a primazia no panorama jurídico-institucional, as novas políticas de desenvolvimento parecem contar com uma intervenção reguladora mais branda, fundada em dispositivos horizontais ou mecanismos de contenção da discricionariedade estatal: favorecem, com isso, os instrumentos provenientes do direito privado. Sob a égide do paradigma Rule of Law, portanto, a intervenção jurídica de caráter goal-oriented, presente, por exemplo, nas regras de planejamento econômico, tem cedido espaço para as iniciativas de autorregulação ou de regulação indireta.

As ideias econômicas neoinstitucionalistas e a concepção de direito como veículo de garantia privada balizam, enfim, o viés das políticas públicas direcionadas a promover as estratégias de desenvolvimento. Os programas governamentais formulados sob a égide do Rule of Law têm uma agenda de intervenção mais tímida do que as políticas desenvolvimentistas confeccionadas no contexto do consenso keynesiano, entre 1950 e 1980. Em vez da alteração dos preços relativos, da definição de estratégias anticíclicas de gastos públicos ou da manipulação de variáveis econômicas, com o objetivo de alterar a precificação das atividades e, com isso, estimular investimentos produtivos em setores estratégicos, o tipo padrão da intervenção do Estado, a partir da década de 1990, passou a ser de viés moderado - restrito a promover um ambiente institucional favorável à atuação de agentes privados (CHANG, 1997, pp. 710-712; KENNEDY, 2006, pp. 128-137). Em última análise, assinala Kennedy, a intervenção desenvolvimentista de abrangência macroeconômica foi suplantada por estratégias políticas implementadas no âmbito microeconômico, comprometidas com a preservação dos mecanismos de seleção de mercado (KENNEDY, 2006, p. 129).

Na realidade, a intervenção econômica do Estado, que tinha como fundamento o diagnóstico das falhas de mercado, passou a ser modulada pela noção de falhas de governo, isto é, a percepção de que as falhas proporcionadas pela regulação são tão ou mais significativas que as próprias falhas de mercado. Influenciados por uma persuasiva literatura dedicada a apontar os problemas (ou a ausência de necessidade) da atuação do Estado na economia (DEMSETZ, 1968; STIGLER, 1973; BAUMOL et al., 1982) e vivenciando a derrocada política da hegemonia keynesiana, formuladores de política e gestores governamentais, em diversos países, passaram a mitigar a participação dos Estados na organização das atividades de mercado. Em boa medida, é este formato de intervenção do Estado, menos confiante na capacidade da regulação pública e mais comprometido com a preservação dos espaços econômicos privados, que tem balizado as políticas de desenvolvimento conduzidas sob a rubrica Rule of Law. O Quadro 1 sintetiza os traços principais deste paradigma. 
Quadro 1 - Paradigmas de Direito e Desenvolvimento

\begin{tabular}{|c|c|c|c|}
\hline & $\begin{array}{l}\text { IDEIAS } \\
\text { ECONÔMICAS }\end{array}$ & $\begin{array}{l}\text { CONCEPÇÃO } \\
\text { DE DIREITO }\end{array}$ & $\begin{array}{l}\text { INTERVENÇÃO } \\
\text { DO ESTADO }\end{array}$ \\
\hline $\begin{array}{r}\text { PARADIGMA } \\
\text { DESENVOLVIMENTISTA }\end{array}$ & $\begin{array}{l}\text { - ECONOMIA KEYNESIANA; } \\
\text { - ADMINISTRAÇÃO } \\
\text { MACROECONÔMICA, GESTÃO } \\
\text { DOS AGREGADOS E PRIMAZIA } \\
\text { DA REGULAÇÃO PÚBLICA }\end{array}$ & $\begin{array}{l}\text { - PREVALÊNCIA DO } \\
\text { DIREITO PÚBLICO; } \\
\text { - RACIONALIDADE } \\
\text { SUBSTANTIVA } \\
\text { - GOAL ORIENTED }\end{array}$ & $\begin{array}{l}\text { - DIREÇÃO ECONÔMICA, } \\
\text { PRIMAZIA DO } \\
\text { PLANEJAMENTO E DO } \\
\text { CONTROLE PÚBLICO SOBRE } \\
\text { AS VARIÁVEIS ECONÔMICAS }\end{array}$ \\
\hline PARADIGMA & $\begin{array}{l}\text { - NOVA ECONOMIA } \\
\text { INSTITUCIONAL; } \\
\text { - ADMINISTRAÇÃO } \\
\text { MICROECONÔMICA; } \\
\text { - PRIMAZIA DO MERCADO } \\
\text { COMO ESPAÇO DE ALOCAÇÃO } \\
\text { DOS RECURSOS ENTRE } \\
\text { PARTICULARES }\end{array}$ & $\begin{array}{l}\text { - APROPRIAÇÃO DO } \\
\text { "LEGADO WEBERIANO"; } \\
\text { - VEÍCULO DE GARANTIA } \\
\text { E SEGURANÇA JURÍDICA; } \\
\text { - RACIONALIDADE } \\
\text { REFLEXIVA } \\
\text { (AUTORREGULAÇ̃̃O) }\end{array}$ & $\begin{array}{l}\text { - INTERVENÇÃO } \\
\text { MODERADA, DIRECIONADA } \\
\text { AO INCREMENTO DO } \\
\text { AMBIENTE DE NEGÓCIOS; } \\
\text { - PRESERVAÇÃO DO } \\
\text { SISTEMA DE PREÇOS }\end{array}$ \\
\hline
\end{tabular}

A difusão do paradigma Rule of Law, na década de 1990, como uma fórmula standard, capaz de garantir novos patamares de crescimento sustentado para as economias menos desenvolvidas, foi particularmente evidente em três experiências, responsáveis pelo reaquecimento dos debates em torno das estratégias adequadas de promoção do desenvolvimento, quais sejam: (i) as reformas econômicas ocorridas nos países latino-americanos; (ii) a transição das economias soviéticas para a ordem de mercado; e (iii) as propostas de alteração institucional recomendadas pelo Banco Mundial aos países da África Subsaariana (SANTOS, 2006, p. 268). Em todos esses episódios, ainda que provenientes de fenômenos históricos diferenciados e guardando pouca identidade entre si, as estratégias recomendadas por agências internacionais e implementadas pelos governos locais tiveram uma plataforma comum: a reforma dos ambientes jurídico-institucionais. Tanto na América Latina como no Leste Europeu, ou na África Subsaariana, prevaleceu o entendimento de que a promoção de boas regras do jogo - do Rule of Law - na forma de promoção da segurança jurídica, de estímulo ao ambiente privado de negócios e de mitigação das ações interventivas do Estado despertaria, por si só, o desenvolvimento econômico e social dos países (KENNEDY, 2003, p. 17).

No caso da América Latina, a consolidação do paradigma Rule of Law foi precipitada pela crise dos programas desenvolvimentistas e pela consequente desorganização econômica registrada em boa parte de seus países, acometidos por altíssimas taxas de inflação e pela restrição na capacidade de realização de investimentos públicos. Ultrapassada a década de 1980, em uma espécie de transição desde um modelo de desenvolvimento baseado na coordenação pública e na substituição de importações, países como o Brasil e a Argentina inauguraram, na década de 1990, um 
audacioso programa de reformas econômicas, orientadas para a promoção do ambiente de mercado, semelhante ao que já havia sido realizado no Chile. Os alvos principais dessas reformas foram a diminuição do deficit fiscal, a redução da abrangência regulatória do Estado, entendida como um fator de limitação ao florescimento de investimentos privados, e, ainda, a melhoria do ambiente de negócios, por meio de dispositivos de proteção a investidores e alterações no funcionamento judicial - considerado excessivamente moroso.

No Brasil, em particular, a condução de tais alterações contou com a realização de reformas jurídico-institucionais intensas, que pressupuseram, entre outros: (i) a promulgação de emendas constitucionais, dedicadas a alterar o papel do Estado na economia (emendas 5, 8, 9 e 19), (ii) a realização de alterações legislativas, para garantir novos marcos reguladores aos setores privatizados (Lei de Concessões, Lei das Telecomunicações, Lei do Petróleo, Lei da Energia Elétrica etc.); e, ainda, (iii) um extenso programa de desestatização, que alterou o papel do Estado no ambiente econômico (BRESSER PEREIRA, 1997, pp. 21-31). Mais recentemente, foram adotadas medidas de teor semelhante, destinadas a impulsionar o ambiente financeiro nacional, com a expectativa de reduzir o custo de captação de recursos e diversificar as fontes privadas de financiamento corporativo (STALLINGS; STUDART, 2006, pp. 222-258). Exemplos disso são as alterações legislativas dedicadas a ampliar o elenco de proteção jurídica a investidores e credores, como a nova Lei de Falências e as alterações na Lei das S.A., assim como os esforços para a criação de novos mercados autorregulados na Bovespa, com regras rígidas de governança corporativa (Novo Mercado, Nível 1 e 2 e Bovespa Mais).

As transformações institucionais ocorridas na América Latina tiveram paralelo no perfil das políticas públicas implementadas nas antigas economias socialistas, após a queda do mundo soviético. Em seus países, o objeto das reformas institucionais foi garantir uma transição destas economias, tradicionalmente centralizadas e planificadas, para uma ordem de mercado, baseada em transações privadas e apenas balizadas pelas regras postas pelo Estado. Países como a Rússia não só realizaram um extenso rol de privatizações, como também promoveram programas de transplante institucional, adotando códigos, padrões legislativos e normas de governança, sobretudo no campo financeiro e corporativo, de outros países, como os Estados Unidos, cujas economias, desde há muito, são baseadas nas operações de mercado. É ilustrativo disso o convite feito por Boris Yeltsin a professores norte-americanos de corporate law a que redigissem um novo código comercial para a Rússia pós-socialista (MILHAUPT; PISTOR, 2008, p. 1). Tais medidas, de acordo com Milhaupt e Pistor (2008), contaram com o amparo de agências como o Banco Mundial, as quais passaram a apoiar, técnica e financeiramente, programas que resultassem na adoção de novas leis e instituições condizentes com uma autêntica economia de mercado nesses países. 
O terceiro evento neste campo, que reforçou a relevância adquirida pelas variáveis jurídico-institucionais na agenda dos programas de desenvolvimento, foi a estratégia de ação do Banco Mundial para a África Subsaariana, na década de 1990. De acordo com Santos (2006, p. 268), o diagnóstico da crise social e econômica vivenciada por aqueles países ensejou a definição de um programa de ação voltado a promover melhorias na capacidade de governança desses Estados. Para tanto, a agência dedicou-se a promover o que denominava Rule of Law - entendido, naquele contexto específico, como reformas institucionais no poder Judiciário, para assim garantir independência decisória e juízos técnicos e, também, uma qualificação no panorama legislativo, facilitando a promulgação de leis afinadas com uma economia baseada na livre iniciativa. Subjacente a essas medidas, figurava a concepção de que a superação dos problemas registrados entre os países africanos demandava a adoção de "instituições corretas", capazes de estimular as atividades econômicas, ao promover uma economia de mercado.

Essas três experiências relativamente recentes indicam, enfim, a prevalência atribuída ao ambiente institucional nas análises e proposições relativas ao crescimento econômico e à geração de renda das nações. Ocorre, contudo, que esta estratégia de intervenção, assentada na difusão do, assim chamado, paradigma Rule of Law, tem dado pouca importância às variações institucionais locais e, com isso, tem desconsiderado um fato relevante: a existência de diferentes arranjos nacionais, forjados ao longo de trajetórias históricas e materializados em uma teia complementar de leis, instituições, valores e padrões culturais - elementos que figuram subjacentes aos regimes de organização social e econômica (TAMANAHA, 2009, pp. 1-41).

É essa trama sócio-jurídica que, em muitos casos, tem tornado ineficazes as recomendações de viés one size fits all. Um exemplo disso têm sido as reformas institucionais conduzidas em sistemas financeiros de países em desenvolvimento, como o Brasil. Influenciadas por análises neoinstitucionalistas realizadas no campo financeiro, tais reformas têm procurado, a um só tempo, mitigar a participação direta dos agentes estatais e incrementar o ambiente jurídico de proteção dos investidores pulverizados. Os resultados, no entanto, sugerem, ao menos no caso brasileiro, algumas limitações do paradigma Rule of Law, seja quanto às suas concepções de economia e de direito, seja quanto às suas estratégias de intervenção política.

\section{O RULE OF LAW NO CAMPO FINANCEIRO:} PROTEÇÃO DOS INVESTIDORES E PROMOÇÃO DOS MERCADOS

No campo da organização dos sistemas financeiros, o paradigma Rule of Law tem permeado análises e proposições de política que procuram tematizar a relação existente entre os atributos jurídico-institucionais e o desempenho do ambiente de investimentos. Ao longo da década de 1990, acompanhando a desenvoltura deste marco teórico 
e político, alguns autores, como Rafael La Porta, Florencio Lopez-de-Silanes, Thorsten Beck, Ross Levine, Asli Demirgürç-Kunt, Andrei Shleifer e Robert Vishny, ${ }^{5}$ passaram a realizar pesquisas dedicadas a avaliar a conexão existente entre a qualidade das regras jurídicas de proteção dos investidores e o funcionamento do mercado de capitais e dos segmentos de intermediação financeira (bancos). Essas análises constituem, desde então, uma influente linha de pesquisa conhecida por Law and Finance, cujos desdobramentos têm balizado iniciativas de reformas institucionais, conduzidas pelos governos nacionais e difundidas pelo Banco Mundial, no âmbito de projetos como o Doing Business. 6

Os autores dedicados a esta imbricação entre direito e financiamento partem dos mesmos pressupostos que conformam o paradigma Rule of Law, ou seja, assumem o mercado de capitais e o segmento bancário privado como os ambientes preferenciais para as transações financeiras e atribuem ao direito um papel de garantidor dos interesses dos agentes econômicos, notadamente acionistas e credores (MILHAUPT; PISTOR, 2008, pp. 17-21). A sua premissa de análise é a de que em um ambiente inseguro, dotado de uma proteção deficiente dos direitos de investidores, ou notabilizado por regras imprecisas e sujeitas a ampla margem de controvérsias, os investidores tendem a restringir a sua disposição em prover recursos monetários, o que, enfim, pode comprometer o volume de capital disponível para as atividades de financiamento corporativo.

A razão para tanto, argumentam Shleifer e Vishny (1997), reside em um problema de agência, o qual é inerente às atividades de financiamento corporativo. A captação de recursos externos por uma empresa, seja no mercado de capitais, seja no sistema bancário, implica o estabelecimento de uma relação de agente-principal entre os tomadores e os investidores: o interesse dos investidores é recuperar o valor aportado, acrescido de rendimentos positivos, e, para isso, eles dependem do comportamento de terceiros - os administradores da firma tomadora dos recursos. Em outros termos, os investidores, ao alocarem recursos em empreendimentos, assumem o papel de principais, na medida em que o atendimento de seus interesses depende da atuação de outros atores - os agentes -, neste caso representados pelos gestores das firmas financiadas. O êxito desta relação agente-principal requer, então, uma disciplina incisiva, sob pena de os investidores (principais) depararem-se com a frustração de suas expectativas, causada por eventuais comportamentos oportunistas de administradores corporativos (agentes). Em suma, tende a haver nesta relação de financiamento um ajuste assimétrico entre investidores e tomadores, o que reclama a estipulação de dispositivos de proteção capazes de mitigar a condição de vulnerabilidade dos principais em relação aos agentes - uma função que só pode ser exercida, por sua vez, pelas regras jurídicas (DAM, 2006, p. 160).

De acordo com esta abordagem, compete ao direito o papel de mitigar os incentivos à adoção de comportamentos oportunistas, estimulando, ao mesmo tempo, a 
realização de transações financeiras mutuamente benéficas. Partilhando dos mesmos postulados da NEI, os autores da Law and Finance tomam o direito como um elemento regulador externo, cuja função é "elevar o custo" das ações autointeressadas e predatórias, tornando-as menos interessantes do que as atuações favoráveis à realização de trocas positivas entre os agentes. A premissa dos estudos da Law and Finance é a de que os instrumentos regulatórios e os mecanismos de governança, se bem desenhados e efetivos, podem incentivar os administradores (agentes) a perseguirem os seus objetivos de modo compatível com os interesses dos demais investidores, ${ }^{7}$ o que afinal tem como resultado agregado o fortalecimento do sistema financeiro nacional (LA PORTA et al., 2000a, p. 6; SHLEIFER; VISHNY, 1997).

Em compensação, assinalam Shleifer e Vishny (1997), ante a ausência de proteção jurídica, o custo de uma gestão oportunista tende a ser pequeno, o que poderia causar efeitos negativos não só para os agentes particulares, mas também para o conjunto do sistema financeiro. Diante da sensação de vulnerabilidade institucional, os investidores, assumidamente racionais, tenderiam a desempenhar comportamentos de autopreservação, tais como a indisponibilidade em participar das operações financeiras ou a precificação exagerada dos recursos disponibilizados (exigência de dividendos e juros expressivos para compensar o risco financeiro), o que resultaria, enfim, em um funcionamento deficiente dos mercados de crédito e de capitais. Por tal razão, para o funcionamento saudável do ambiente financeiro, são indispensáveis a previsão e a efetividade de um universo de direitos de proteção de acionistas e credores (LA PORTA et al., 2000a; SHLEIFER; VISHNY, 1997).

Essas premissas foram aplicadas em uma série de estudos empíricos, realizados por La Porta et al. (1997, 1998, 2000a), dedicados a comparar a qualidade da proteção jurídica oferecida aos investidores no âmbito dos sistemas financeiros nacionais. Partindo de um conjunto previamente definido de ferramentas jurídicas, entendidas como os direitos e as garantias mais adequados para assegurar os interesses dos investidores,${ }^{8}$ os autores realizaram comparações (estudos cross-country) entre os ordenamentos jurídicos de 49 países, previamente classificados conforme a origem de seus sistemas jurídicos: (i) common law, (ii) civil law de origem francesa, (iii) civil law de origem germânica e (iv) sistema escandinavo. ${ }^{9}$

Os resultados das regressões sugerem que os países de common law apresentam uma maior incidência das ferramentas de proteção definidas como parâmetros de análise, ao passo que os países herdeiros de uma tradição de civil law de origem francesa apresentariam os piores índices de salvaguarda. ${ }^{10}$ Além disso, os países originários da common law gozariam de uma maior dispersão acionária e de uma maior atividade do mercado de capitais - medido pelo volume de operações de abertura de capital (IPOs) enquanto os países com um sistema de civil law francesa mostrariam uma maior concentração do capital nas sociedades, um menor volume de transações no mercado de capitais e também uma menor dimensão do mercado de crédito. A conclusão dessas 
análises sugere, portanto, que os países de common law são titulares de sistemas financeiros mais desenvolvidos, o que seria, enfim, uma função da qualidade das ferramentas jurídicas de proteção de acionistas e credores.

Percorrendo essa mesma trajetória teórica e metodológica, no trabalho Government Ownership of Banks, La Porta, Lopez-de-Silanes e Shleifer (2000b) examinam a relação (supostamente) existente entre as deficiências na proteção jurídica dos investidores e a estipulação de propriedade estatal no setor bancário. Divididos os países pela origem de seus sistemas legais, os autores assinalam que os países de common law são os que apresentam a menor incidência de participação dos governos no setor bancário, ao passo que, nos países de civil law francesa, a presença direta do governo nesse segmento é a mais expressiva (LA PORTA et al., 2000b). É também nesses países que os bancos de desenvolvimento figuram com mais frequência.

As razões apresentadas para essas diferenças remontam ao argumento central dos estudos de viés Law and Finance: nas economias com um menor índice de Rule of Law, isto é, com uma menor proteção aos direitos de propriedade, prevalece a propriedade pública no setor bancário. A criação de bancos públicos é entendida pelos autores como uma espécie de second best institucional, isto é, uma solução alternativa introduzida por governos que são incapazes de estabelecer um ambiente institucional adequado, informado por um regime de proteção da propriedade privada e pela garantia de efetividade dos contratos. Sendo assim, ante as fragilidades da organização jurídica, o Estado compensaria as incertezas dos investidores privados, retraídos em razão da debilidade do ambiente institucional. Essa seria, no entanto, uma alternativa insatisfatória: os bancos públicos seriam mais ineficientes do que os bancos privados, e as análises estatísticas sugeririam uma correspondência negativa entre a prevalência de um setor financeiro público e o crescimento econômico dos países - as economias baseadas em bancos estatais apresentariam menores taxas de crescimento (LA PORTA et al., 2000b).

As conclusões de análises como essa têm recebido atenção e influenciado posicionamentos para além dos limites do ambiente acadêmico. A premissa de que determinado perfil de proteção jurídica dos investidores é uma variável causal para a correção de distorções no funcionamento dos mercados de crédito e de capitais e, consequentemente, para um incremento no volume das transações financeiras tem informado tanto a operação real do ambiente de negócios, como a agenda das políticas públicas. De um lado, projetos como o Doing Business, do Banco Mundial, ao classificarem os países conforme o nível da proteção jurídica oferecida aos agentes econômicos, valendo-se para isso dos critérios apresentados pelos estudos Law and Finance, têm influenciado a decisão de investidores, balizando assim o funcionamento real das economias nacionais (FABIANI, 2009, p. 42). De outro lado, as iniciativas de reformas institucionais dirigidas ao setor financeiro também passaram a incorporar esses diagnósticos, direcionando as políticas públicas para um incremento da proteção dos acionistas e credores privados, nos moldes indicados pelos estudos de La Porta et al. 
(MILHAUPT; PISTOR, 2008, pp. 20-21). Em última análise, tais políticas têm perseguido uma determinada imagem modal de sistema financeiro, consubstanciada pela prevalência de investidores privados, em mercados de capitais ou de créditos.

A repercussão deste paradigma Rule of Law no campo financeiro também encontrou guarida no panorama brasileiro. Ao longo da década de 1990 e no início da de 2000, inspiradas nessas análises e recomendações de política, diversas alterações jurídico-institucionais no funcionamento do sistema financeiro nacional foram conduzidas, com a finalidade de permitir uma transição desde um modelo de financiamento baseado nos bancos públicos para um regime de mercado, assentado em agentes privados. Em um espaço de tempo não superior a uma década, registraram-se iniciativas bastante significativas na organização financeira nacional: boa parte dos bancos estaduais foi privatizada, o mercado bancário foi aberto para a competição externa, novas leis foram promulgadas para garantir segurança jurídica nas transações financeiras, e o mercado de capitais passou a adotar novos padrões de governança corporativa.

Como se procurará argumentar a seguir, em boa medida, o viés dessas reformas parece ter repetido esforços que já haviam sido conduzidos no país entre 1964 e 1967, quando reformadores institucionais procuraram fortalecer o mercado financeiro nacional. Tal como na década de 1960, as medidas da década de 1990 também não foram capazes de alterar o peso dos bancos públicos no financiamento corporativo brasileiro (ao menos nos aportes de longo prazo e de maior risco), a despeito do incremento de mecanismos institucionais e de regras de incentivo aos mecanismos de mercado. $\mathrm{O}$ BNDES, em particular, continua sendo um ator-chave na dinâmica financeira nacional, garantindo recursos de longo prazo e apresentando uma respeitável eficiência operacional, com margens expressivas de lucro anual. ${ }^{11}$

Este descasamento entre os diagnósticos e prognósticos dos programas de incremento institucional identificados pelo slogan Rule of Law e o funcionamento do ambiente financeiro nacional levarão à conclusão dos limites deste paradigma no campo do Direito e Desenvolvimento. Em particular, esta associação de ideias econômicas, concepção de direito e vetor de política não tem sido capaz de reconhecer que as economias nacionais apresentam diferentes alternativas de arranjo institucional. Em outros termos, se é verdade que o ambiente jurídico-institucional importa para o desenvolvimento econômico e para as atividades financeiras, é igualmente verdadeiro que existem diferentes modelos de organização das relações econômicas. Um deles é a propriedade estatal no segmento bancário.

\section{ESCAPANDO DO MODELO:}

\section{A PREVALÊNCIA DO BNDES NO AMBIENTE FINANCEIRO NACIONAL}

A trajetória brasileira de financiamento corporativo destoa das análises e recomendações de política afinadas com as estratégias de promoção do Rule of Law, tal como 
identificadas neste trabalho: a presença do Estado como agente financeiro tem sido uma característica bastante presente na organização econômica do país. Em função das falhas apresentadas pelos mercados financeiros nacionais, tanto de capitais como de crédito, seja na captação de recursos, seja na sua alocação para empreendimentos portadores de externalidades positivas para o desenvolvimento, os agentes financeiros públicos têm se responsabilizado pelo estabelecimento de mecanismos compulsórios de poupança e pelo direcionamento do crédito para os projetos corporativos identificados como estratégicos. O desempenho de atores como o Banco do Brasil, a Caixa Econômica Federal, o BNH e, notadamente, o BNDES, ao longo das últimas décadas, é exemplo deste modo de organização institucional, no qual o Estado exerce um papel proeminente na mediação das relações financeiras. Desde o início da empreitada industrial até o momento presente, tem cabido ao Estado a maior parte dos financiamentos de longo prazo do país, assim como também tem sido sua responsabilidade formar a base financeira (funding) a qual tem dado suporte a essa forma de intervenção.

Durante o período desenvolvimentista, o mercado de capitais cumpriu um papel bastante residual na garantia dos recursos de longo prazo e só passou a ter alguma relevância a partir da década de 1970, com a promulgação da Lei do Mercado de Capitais, Lei 4.728, de 1965, com a Lei das S.A. (Lei 6.404, de 1976) e com a definição de programas de incentivo tributário aos investimentos no mercado acionário (TRUBEK et al., 1972), mesmo assim exercendo, ainda, uma função marginal no conjunto do sistema financeiro nacional. Entre 1970 e 1990, por exemplo, o volume das emissões primárias de ações não ultrapassou o patamar anual de 0,5\% do PIB (MONTEIRO FILHA, 1994, p. 46), e o número de empresas listadas na BOVESPA nunca chegou a 500 companhias (MENDONÇA DE BARROS et. al., 2000, p. 30). Mesmo nos anos recentes, após um aquecimento no número de operações de abertura de capital e a criação de novos níveis de governança na BOVESPA (Nível 1, Nível 2 e Novo Mercado), a dimensão das captações primárias ainda não superou, de modo consistente, o volume de recursos disponibilizados pelos agentes públicos: com exceção do ano de 2007, o volume de desembolsos do BNDES tem sido superior ao volume de recursos captado via ações e debêntures. ${ }^{12}$

Esta diminuta participação do mercado de capitais teve paralelo no segmento bancário brasileiro, que, da mesma forma, não desempenhou o papel de provedor de recursos de longo prazo durante a industrialização do país. Diferentemente do que ocorreu no Japão ou na Alemanha, em que os bancos substituíram a ausência do mercado de capitais na oferta de recursos financeiros industriais (ZYSMAN, 1984, p. 61), no Brasil, os bancos privados especializaram-se na intermediação financeira de curto prazo e baixo risco. Um padrão de comportamento que, apesar das alterações nas condições jurídico-institucionais, ainda perdura neste segmento (STALLINGS; STUDART, 2006, pp. 244-245). É ilustrativo disso o expressivo custo dos recursos 
disponibilizados pelo segmento bancário, cuja taxa média de juros, na casa dos 50\% ao ano, tem se mostrado mais adequada às operações de curto prazo do que às de longo prazo.

As carências demonstradas pelas fontes privadas nacionais, desde o início da estratégia desenvolvimentista, resultaram na constituição de um modelo alternativo de financiamento, baseado na regulação institucional do sistema bancário (SCHAPIRO, 2009, pp. 72-83), isto é, um arranjo de governança que tem contado com a participação presencial do Estado como agente financeiro. Assim como ocorrido em outros países em desenvolvimento, como Coreia do Sul, Taiwan e México, ${ }^{13}$ foram os agentes estatais que supriram, no Brasil, ambas as ausências, a do mercado de capitais e a do segmento bancário, encarregando-se de disponibilizar os recursos necessários para os investimentos de maior risco e com prazo longo de retorno. Nessa medida, o papel desempenhado pelo direito extrapolou a função de meramente garantir os interesses de acionistas e credores privados. A sua efetiva função foi a de constituir um sistema de financiamento de longo prazo, para o que foi necessário o estabelecimento de um regime de propriedade estatal no segmento bancário, suprindo, assim, a carência do investidor privado. Desde então, o modelo brasileiro de financiamento tem sido baseado nestes dois elementos: (i) a poupança compulsória, formada por meio do poder de arrecadação do Estado e (ii) o direcionamento dos recursos pelos agentes estatais (pelos bancos públicos).

Uma das primeiras formalizações deste diagnóstico de falha do mercado financeiro nacional foi apresentada já no início da década de 1950, como conclusão dos trabalhos da Comissão Mista Brasil-Estados Unidos (1951-1953), formada por técnicos de ambos os países e estabelecida com o propósito de apresentar um estudo sobre os problemas do processo brasileiro de industrialização. Como resultado da Comissão adveio um acordo bilateral, destinado a mitigar as lacunas financeiras apresentadas pelo país: o governo brasileiro teria acesso a recursos internacionais e, em contrapartida, deveria garantir a mobilização de recursos nacionais, formando assim um volume de recursos que seria empregado em setores críticos, como o ferroviário e o elétrico (CURRALERO, 1998; MONTEIRO FILHA, 1994). A formação da contrapartida nacional contou com a adoção de um mecanismo de poupança compulsória: a Lei 1.474, de 1951, instituiu uma alíquota adicional ao Imposto de Renda, o que permitiu a formação do Fundo de Reaparelhamento Econômico. Em 1952, a Lei 1.628 instituiu a autarquia federal Banco Nacional de Desenvolvimento Econômico (BNDE), a quem foi encarregada a administração e o gerenciamento da aplicação desses recursos, em conformidade com as diretrizes consignadas nos planos nacionais de desenvolvimento. A constituição do BNDES ${ }^{14}$ foi, portanto, uma resposta institucional às lacunas do sistema financeiro privado e resultou, desde então, na conformação de um arranjo financeiro alternativo, baseado na captação e no direcionamento público dos recursos. 
Ao longo das décadas de 1950, 1960 e 1970, o Banco se consolidou como um dos principais agentes financeiros do país, tendo sido encarregado da administração de diversos outros fundos federais, igualmente instituídos por meio de recursos tributários e destinados ao financiamento de empreendimentos industriais (LAFER, 2002). Em cada período, respondendo aos desígnios dos planos de desenvolvimento, o Banco pautou a sua intervenção financeira no atendimento das prioridades estabelecidas pelo Governo. Entre 1956 e 1961, por exemplo, durante o Plano de Metas, primeira grande iniciativa de planejamento econômico do país, o BNDES direcionou a sua intervenção aos setores de energia elétrica e siderurgia (MONTEIRO FILHA, 1994, pp. 66-82), sendo o principal agente financeiro de seus empreendimentos. Já entre 1974 e 1979, na segunda grande experiência de planejamento da economia nacional, o II Plano Nacional de Desenvolvimento (II PND), o BNDES exerceu um papel central na provisão de recursos financeiros para a indústria nacional, sobretudo nos segmentos de: insumos básicos (siderurgia, química, fertilizantes e papel e celulose); infraestrutura (energia elétrica e transportes ferroviários) e bens de capital (equipamentos mecânicos e elétricos). Nessa etapa do desenvolvimentismo, o Banco não só foi o principal provedor nacional de recursos para os empreendimentos corporativos (públicos e privados), como também o fez de modo a vincular a sua intervenção às prioridades governamentais, favorecendo os segmentos identificados como estratégicos para o programa de transformação industrial do país (CURRALERO, 1998).

Notadamente no contexto do II PND, o Banco passou, ainda, a exercer o papel de um autêntico experimentador institucional, testando novas modalidades de estruturação de financiamentos, que acabaram por se irradiar para o conjunto do sistema financeiro (SCHAPIRO, 2009, pp. 92-102). Este é o caso das operações de capital de risco, inauguradas pelo BNDES, entre 1974 e 1980, por meio de companhias subsidiárias, dedicadas a estabelecer participações societárias em empresas: a EMBRAMEC, voltada para as operações no setor de bens de capital; a FIBASE, para o setor de insumos básicos; e a IBRASA, para empreendimentos em empresas nacionais em geral. Foram as operações dessas empresas, depois reorganizadas em uma única companhia de participações - a BNDESpar -, que iniciaram no Brasil os investimentos de private equity e venture capital, o que acabou por contribuir não só para o patamar de capitalização das empresas nacionais, como também para o desenvolvimento de novos instrumentos financeiros no mercado de capitais brasileiro.

Apesar do saldo positivo dessas intervenções, as dificuldades apresentadas para o desenvolvimento do segmento financeiro privado nacional deram ensejo a algumas iniciativas de reformas institucionais, destinadas a mitigar o peso da participação estatal e a estimular um incremento do mercado de capitais e do setor bancário nacional. Na década 1960, por exemplo, notadamente entre 1964 e 1967, o Brasil vivenciou um período marcado por diversas alterações legislativas e institucionais, 
cujo propósito foi o de fortalecer o ambiente financeiro, o que permitiria uma redução da dependência do Estado como agente de investimento. Na década de 1990, foram realizadas reformas de viés semelhante, igualmente orientadas a favorecer as transações financeiras privadas, voltadas, portanto, para uma diversificação do modelo brasileiro de financiamento. Em ambos os períodos, as reformas tiveram por objeto o aperfeiçoamento do ambiente de negócios, valendo-se para tanto de iniciativas destinadas a estabelecer regras de proteção aos investidores, mecanismos de governança e, ainda, a ampliação da competição, entendida como um fator de indução ao bom funcionamento dos mercados de crédito e de capitais.

Todavia, como será relatado a seguir, o resultado de ambas as iniciativas, embora palpável em alguns aspectos, não foi capaz de alterar o curso do arranjo brasileiro, que ainda conta com os agentes estatais para boa parte das captações e operações de longo prazo. Após as duas reformas (das décadas de 1960 e 1990), os bancos públicos continuam desempenhando um papel-chave na economia brasileira, sendo responsáveis pela maior parte dos financiamentos de investimentos.

\section{I AS REFORMAS FINANCEIRAS DA DÉCADA DE I960}

Na década de 1960, notadamente a partir de 1964, o diagnóstico dos formuladores de política pública era o de que o país carecia de um sistema financeiro capaz de garantir, de modo sustentável, as contínuas necessidades de investimento demandadas pelas estratégias de desenvolvimento industrial. Por tal razão, foram promulgados diplomas legislativos importantes, como a Lei do Mercado de Capitais - 4.728/65 - e a Lei do Sistema Financeiro Nacional - 4.595/64 -, que criou o Banco Central e lhe outorgou o mandato de agente regulador do segmento bancário. Foram criados ainda os bancos de investimento e de desenvolvimento (Lei 4.728/65), que deveriam cumprir o papel de agentes financeiros de longo prazo, o que viabilizaria a constituição de um novo mercado no segmento bancário. Os bancos de investimento não poderiam receber depósitos à vista como os demais bancos, mas, em compensação, poderiam realizar operações com valores mobiliários no mercado de capitais (NUSDEO, 1977, pp. 253-256). A expectativa era a de que esses bancos viessem a desempenhar o papel de agentes financeiros para os empreendimentos de alto risco e longo prazo, para o que poderiam se valer da realização de operações estruturadas, com valores mobiliários, por exemplo. O êxito de tal medida poderia resultar, portanto, em uma diversificação das fontes financeiras nacionais - era este o objetivo da política.

Os bancos públicos e as empresas estatais, até então responsáveis por boa parte dos investimentos realizados na economia brasileira, também foram objeto das reformas adotadas no período. Como parte da proposta de reforma administrativa institucionalizada no Decreto-lei 200/67, destinada a dar eficiência operacional aos agentes estatais, as empresas públicas e sociedades de economia mista passaram a 
contar com uma menor dependência do governo e com um estímulo para autofinanciar as suas atividades (COUTINHO; REICHSTUL, 1977, pp. 71-72). Já os bancos públicos foram encarregados de funções específicas, para com isso reforçar a disposição de segmentar o mercado financeiro nacional: (i) ao Banco do Brasil coube o financiamento agrícola; (ii) ao Banco Nacional de Habitação (BNH), criado pela lei 4.320/64, coube a missão de alocar os fundos compulsórios do FGTS no financiamento habitacional; (iii) ao BNDES e aos bancos de desenvolvimento estaduais, coube a tarefa de garantir recursos para as atividades industriais e de infraestrutura.

As alterações introduzidas pelas reformas financeira e administrativa tiveram o propósito de mitigar o caráter Estado-centrado do desenvolvimento econômico, procurando, desse modo, reduzir a prevalência dos agentes públicos e abrir espaço para a formação de um segmento privado de investimento e financiamento. A proposta prevalecente era a de fortalecer o ambiente jurídico-institucional, de modo a aprofundar e enraizar o ambiente financeiro privado (financial deepening) e assim permitir uma transição desde um modelo baseado no Estado para um modelo financeiro de mercado (YAZBEK, 2007, p. 61). É por esta razão que se procurou garantir, por exemplo, autonomia financeira para as empresas estatais, que, até então, drenavam os recursos públicos, como os do BNDES, para as suas políticas de expansão.

Entretanto, apesar de alguns bons resultados obtidos na diversificação do estoque de ferramentas financeiras e no alargamento dos mercados de crédito e de capitais, que passaram a contar com novas entidades, como os bancos de investimento, as reformas institucionais do período não conseguiram superar os tradicionais constrangimentos apresentados pelo mercado privado. Essa avaliação, particularmente no que se refere ao mercado de capitais, é partilhada por consultores do mercado financeiro, que anos mais tarde se encarregariam de apresentar as bases de uma nova reforma institucional:

A fragilidade do mercado de capitais brasileiro não é recente. Nunca, na história do capitalismo brasileiro, o mercado de capitais cumpriu um papel proeminente, alavancando recursos para investimentos de alta intensidade de capital e longos prazos de maturação. Nem mesmo após o PAEG que, reformulando toda a institucionalidade do sistema financeiro brasileiro entre 1964 e 1967, "teoricamente” criava as condições para o florescimento do mercado de capitais no Brasil. (MB ASSOCIADOS, 2000, p. 5)

Ao apresentar um balanço destas reformas, Monteiro Filha (1994, pp. 47-56) concorda com esse diagnóstico e assinala que, não obstante os esforços perpetrados por policy makers e gestores públicos, o mercado financeiro nacional permaneceu ainda bastante incipiente. As atividades mobiliárias seguiram desempenhando um 
papel bastante restrito no universo financeiro, e o segmento bancário, inclusive os bancos de investimento, continuou a concentrar a sua atuação em operações de curto prazo e no financiamento do capital de giro das empresas - atividades de menor risco. Com isso, a parte substancial do financiamento de longo prazo permaneceu sendo exercida por meio da regulação institucional, baseada na poupança compulsória e no crédito direcionado. Não por acaso, foi o BNDES que assumiu o papel de coordenador e financiador dos investimentos industriais realizados durante o II PND, menos de dez anos após a primeira onda de reformas financeiras.

\subsection{As REFORMAS FINANCEIRAS DA DÉCADA DE I990}

Na década de 1990, foram implementadas políticas de reforma institucional com viés semelhante ao das iniciativas de diversificação financeira, ocorridas entre 1964 e 1967. Nesse segundo período, as iniciativas de alteração institucional se situaram em um marco de referência mais abrangente, que envolveu uma sucessão de reformas econômicas destinadas a alterar o modelo de organização econômica do país. Procurando reagir à crise da estratégia desenvolvimentista, as reformas do período tiveram por objeto a desestatização da economia brasileira, o que resultou em um extenso programa de privatização, responsável pela alienação de mais de 150 empresas estatais em um período inferior a uma década. Este mesmo vetor de reformas, destinado a amplificar os espaços de transação sob as regras de mercado, também teve desdobramentos no ambiente financeiro nacional.

A partir de 1994, quando as taxas de inflação atingiram um patamar de estabilidade e o sistema de preços voltou a funcionar como um agente de coordenação de mercado, foram implementados três eixos principais de reformas: (i) a reorganização do segmento financeiro público; (ii) a abertura do segmento bancário para competidores estrangeiros; e (iii) alterações legislativas e iniciativas de autorregulação no mercado de capitais.

A reorganização do segmento bancário público contou com dois programas implementados pelo Governo Federal: (i) Programa de Incentivo à Redução do Setor Público Estadual na Atividade Bancária (PROES) e (ii) Programa de Fortalecimento das Instituições Financeiras Federais (PROEF). O primeiro dos programas, PROES, com início em 1997, teve o propósito de reduzir a participação dos estados da Federação no segmento bancário. O programa consistia em um conjunto de incentivos para que os estados viessem a privatizar os seus bancos públicos: aqueles que aderissem ao programa receberiam aportes de recursos necessários para recapitalizar as suas instituições financeiras, tornando-as aptas a serem alienadas. O resultado alcançado foi relevante: o número de bancos públicos estaduais passou de 32, em 1995, para 14, em 2003 (CINTRA, 2006; STALLING; STUDART, 2006). Alguns anos depois, em 2001, um programa semelhante foi direcionado aos bancos federais - o PROEF. No âmbito de sua execução, foram adotadas, por exemplo, novas regras 
de supervisão, semelhantes às existentes para os bancos privados, e foi criada, ainda, uma sociedade de propósito específico, a Empresa Gestora de Ativos (EMGEA), que assumiu dívidas de difícil recuperação dos bancos federais, garantindo assim a solvabilidade do sistema público. ${ }^{15}$ Como resultado do programa, os bancos federais, recapitalizados, passaram a adotar padrões de atuação e regras de governança corporativa semelhantes às das demais instituições financeiras. Um exemplo disso é o Banco do Brasil, que, em 1996, teve de contar com um aporte significativo do Tesouro Nacional e, anos mais tarde, passou a ser uma companhia listada no Novo Mercado da Bovespa - o segmento mais exigente com relação às regras de governança corporativa.

A segunda alteração institucional relevante no período foi a abertura do segmento bancário à concorrência internacional. Esta medida tinha uma inspiração semelhante às demais reformas ocorridas no período, qual seja, fortalecer os mecanismos de mercado na organização financeira. Particularmente, a internacionalização do segmento procurava responder, via ampliação da competição, a um problema crônico do setor de crédito brasileiro: o alto custo dos spreads nas operações de crédito. Apostava-se que a concorrência oferecida pelos bancos estrangeiros, associada ao efeito da demonstração de sua atuação na concessão de financiamentos, disciplinaria os demais atores do sistema bancário nacional, o que, afinal, resultaria em uma diminuição dos custos de captação de recursos. Entre 1996 e 2006, o número de instituições financeiras sob controle estrangeiro foi ampliado de maneira substantiva, passando de 25 para 48. Esse acréscimo do número de atores também se refletiu na composição dos ativos do setor bancário: entre 1996 e 2006, este grupo passou do patamar de 10,51\% dos ativos totais para $21,70 \%$ do total. ${ }^{16}$

As reformas processadas no panorama bancário brasileiro, direcionadas a incrementar a parcela privada do mercado de crédito, tiveram paralelo nas modificações ocorridas no mercado de capitais. Neste segmento, foram adotados dois tipos de medidas institucionais: (i) uma nova legislação societária (Lei 10.303, de 2001) e (ii) regras de autorregulação, confeccionadas pelos próprios agentes de mercado. Ambas as medidas, destinadas a qualificar as regras de governança corporativa, apresentam uma filiação ainda mais evidente com as análises e proposições da literatura Law \& Finance. Os documentos que referenciaram essas iniciativas adotaram as mesma premissas contidas nos trabalhos de La Porta et al. (1997, 1998) e assumiram a proteção dos investidores privados e a retração da participação estatal como as variáveis decisivas para um incremento do mercado de capitais no Brasil. Em uma passagem do documento Desafios e Oportunidades para o Mercado de Capitais Brasileiro, elaborado pela MB Associados (2000) para a Bovespa, a influência dessa literatura é bastante acentuada:

Uma série de trabalhos mostra que países que oferecem maior proteção aos minoritários apresentam 1) mercados acionários relativamente maiores; 
2) menor grau de concentração da propriedade das empresas abertas;

3) maior número de companhias abertas (normalizado pelo tamanho da população); 4) as empresas captam mais recursos através do mercado acionário; e 5) a avaliação de mercado das empresas, medida através da relação entre valor patrimonial e valor de mercado, é comparativamente maior. Baseados nas evidências mencionadas, concluímos que o principal instrumento de promoção do mercado de capitais deverá ser a governança corporativa que, de um lado, é, entre outras coisas, quem dará a segurança necessária ao investidor e, de outro, valorizará as empresas que, assim, poderão ter um custo de captação menor. (p. 10) ${ }^{17}$

As propostas de fortalecimento dos instrumentos de proteção dos investidores e de melhoria do ambiente de governança societária, no plano legislativo, foram incorporadas pela Lei 10.303/01, que permitiu uma reforma na Lei das S.A., dispondo, entre outros, de novos direitos para os acionistas minoritários. Além de firmar uma nova proporção entre ações com e sem direito a voto, fixando o limite de preferenciais em 50\% do capital, a nova lei restabeleceu a proteção ao acionista minoritário nos casos de alienação do controle da companhia pelo majoritário (tag along). A redação original da Lei das S.A. autorizava as sociedades anônimas a emitir até dois terços das ações sem direito a voto, o que se entendia como prejudicial ao equilíbrio de forças intracompanhia. Já o tag along, embora fosse previsto na Lei 6.404/76, havia sido suprimido, em 1997, pela Lei 9.457.

No âmbito da autorregulação, a reforma legislativa foi acompanhada pela introdução de novas regras, voluntariamente adotadas pelas empresas listadas. $\mathrm{Na}$ realidade, foram definidos níveis diferentes de exigências regulatórias a serem atendidas pelas companhias interessadas - cada um desses níveis compõe um padrão de mercado da Bovespa. Com isso, além do mercado tradicional, a bolsa paulista estabeleceu outros três níveis de mercados de valores: os mercados de Nível 1 e Nível 2 e o Novo Mercado. ${ }^{18}$ As regras do Nível 1 são particularmente voltadas à garantia de um patamar mais elevado de transparência; as regras do Nível 2, para além da transparência, apresentam exigências relativas ao padrão de demonstração financeira e a possibilidade de voto para os preferencialistas em algumas situações, tais como fusões e aquisições. Já o Novo Mercado reúne um conjunto mais abrangente e incisivo de regras de governança: (i) o conselho de administração das companhias listadas deve contar com no mínimo 20\% de representantes independentes; (ii) 25\% das ações das companhias devem ser mantidas em livre negociação no mercado (free float); (iii) só podem ser emitidas ações com direito a voto (não há ações preferenciais no Novo Mercado); e (iv) o tag along é superior ao da Lei 10.303/01 - em caso de alienação do controle, os minoritários têm direito ao mesmo valor percebido pelo controlador (tag along de 100\%). 
As reformas ocorridas no sistema bancário e no ambiente do mercado de capitais provocaram alterações no panorama financeiro nacional. A participação dos bancos públicos (estaduais e federais) nos ativos totais do segmento, por exemplo, foi sensivelmente reduzida, passando de 50,91\%, em 1996, para 29,64\%, em 2006, ao passo que os bancos privados passaram de um patamar de 38,28\% dos ativos (em 1996) para 47,12\% dos ativos totais (em 2006). ${ }^{19}$ O volume de operações no mercado de capitais também foi incrementado: o volume de emissões primárias de ações e de títulos de dívida (debêntures) apresentou uma variação positiva nos últimos anos (até 2008). O ano de 2007, em particular, contou com um volume expressivo de IPOs na bolsa. Só no Novo Mercado foram 41 empresas, um aumento considerável em relação a 2006, quando ocorreram 23 operações desse tipo.

Entretanto, tal como ocorrido com as reformas realizadas na década de 1960, as alterações introduzidas na década de 1990, embora tenham produzido dados expressivos, não foram suficientes para alterar a característica central do modelo brasileiro de financiamento. As operações de longo prazo e alto risco ainda dependem dos agentes estatais.

\subsection{A persistência do modelo brasileiro de financiamento}

Apesar das reformas institucionais ocorridas na década de 1990, a maior parte do financiamento de longo prazo da economia brasileira continua sendo realizada pelos bancos estatais, em especial pelo BNDES. Dados apresentados por Stalling e Studart (2006, pp. 222-258), em um estudo comparado de sistemas financeiros latino-americanos, indicam que só o BNDES responde pela maior parte de todos os recursos de longo prazo concedidos no país. Esta percepção, associada ao fato de que o Banco do Brasil e o BNDES são ainda os principais provedores de recursos para pequenas e médias empresas, levou os autores a concluir que os agentes públicos ainda desempenham um papel-chave na economia nacional:

The public banks continue to play a vital role in Brazil, contrary to expectations.

Both the government and those supporting the reforms in the 1990s believed the changes would revolutionize the credit market. In particular, they expected the entry of foreign banks to expand credit significantly and broaden access for those normally excluded, such as SMEs and poorer households. They further assumed that the public banking sector would continue to shrink because it was less competitive than private, especially foreign, banks. The results turned out differently than anticipated, however, and public banks continue to play a key role. (p. 245)

$\mathrm{Na}$ realidade, muito embora os bancos privados tenham ampliado a oferta de crédito nos últimos dez anos, a maior parte dos recursos oferecidos continua a ser de curto prazo, destinados ao consumo das famílias. Este é o caso, por exemplo, do 
crédito consignado, uma modalidade financeira instituída pela Lei 10.820, de 2003, que já responde por boa parte de todas as operações de crédito pessoal. Trata-se, tipicamente, de um recurso de baixo risco (garantido pela conta-salário) e com vencimento no curto prazo (CINTRA, 2006). Uma plausível justificativa para a persistência desta segmentação do mercado financeiro entre bancos públicos-longo prazo e bancos privados-curto prazo, é o elevado valor dos spreads cobrados pelas instituições financeiras privadas, situado no patamar de 50\% ao ano (BANCO MUNDIAL, apud FABIANI, 2009, p. 14). Este fator tem tornado os empréstimos bancários públicos praticamente a única fonte viável de recursos para determinados tipos de empreendimentos.

O custo do recurso do BNDES tem como base, via de regra, a Taxa de Juros de Longo Prazo (TJLP), que é definida pelo Conselho Monetário Nacional. A TJLP é o valor que o BNDES paga para utilizar os recursos do Fundo de Amparo ao Trabalhador (FAT), um fundo de poupança compulsória, previsto pela Constituição Federal (art. 239, $\S 1^{\circ}$, Disposições Constitucionais Gerais), ${ }^{20}$ para garantir recursos aos programas de desenvolvimento econômico. $\mathrm{O}$ valor arbitrado para a TJLP tem sido significativamente inferior ao dos spreads bancários, situando-se atualmente na faixa dos 6\% ao ano. Com essa diferença no custo dos recursos, o volume de desembolsos anuais do BNDES tem apresentado um crescimento substancial, passando dos R \$ 10 bilhões desembolsados em 1994 para os cerca de R \$ 90 bilhões desembolsados em 2008 (Gráfico 1). Uma evolução que sugere a dimensão da participação do BNDES na economia brasileira, mesmo após a estabilização financeira e as reformas de mercado.

Gráfico 1 - Evolução dos desembolsos anuais do BNDES

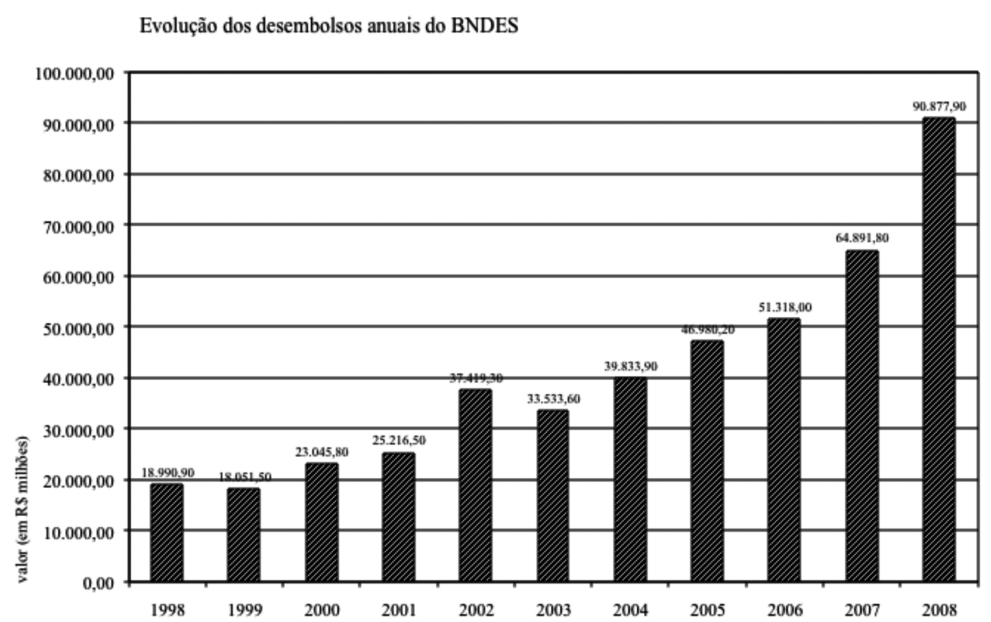

Fonte: BNDES 
Em relação à participação do mercado de capitais, muito embora os anos de 2005, 2006 e 2007 tenham registrado um comportamento ascendente no volume de operações, a sua densidade como fonte financeira ainda é questionável. Até o início desse triênio positivo, um dos temas em debate era justamente a redução do número de empresas de capital aberto, ou seja, na contramão das expectativas, empresas listadas estavam fechando o capital. Ademais, em uma perspectiva temporal mais ampla, o mercado de capitais ainda evidencia um comportamento instável (STALLING; STUDART, 2006), o que não permite uma afirmação peremptória de que tenha se constituído no ator-chave de financiamento da economia brasileira. Os dados, aliás, confirmam esta desconfiança: uma comparação do volume de recursos captados via emissão primária de debêntures e de ações com o montante desembolsado somente pelo BNDES, entre 1998 e 2008, indica justamente que a participação do banco público ainda é mais expressiva que a do mercado de capitais (gráfico 2).

Gráfico 2 - Desembolsos do BNDES em comparação com emissões primárias de ações e de debêntures

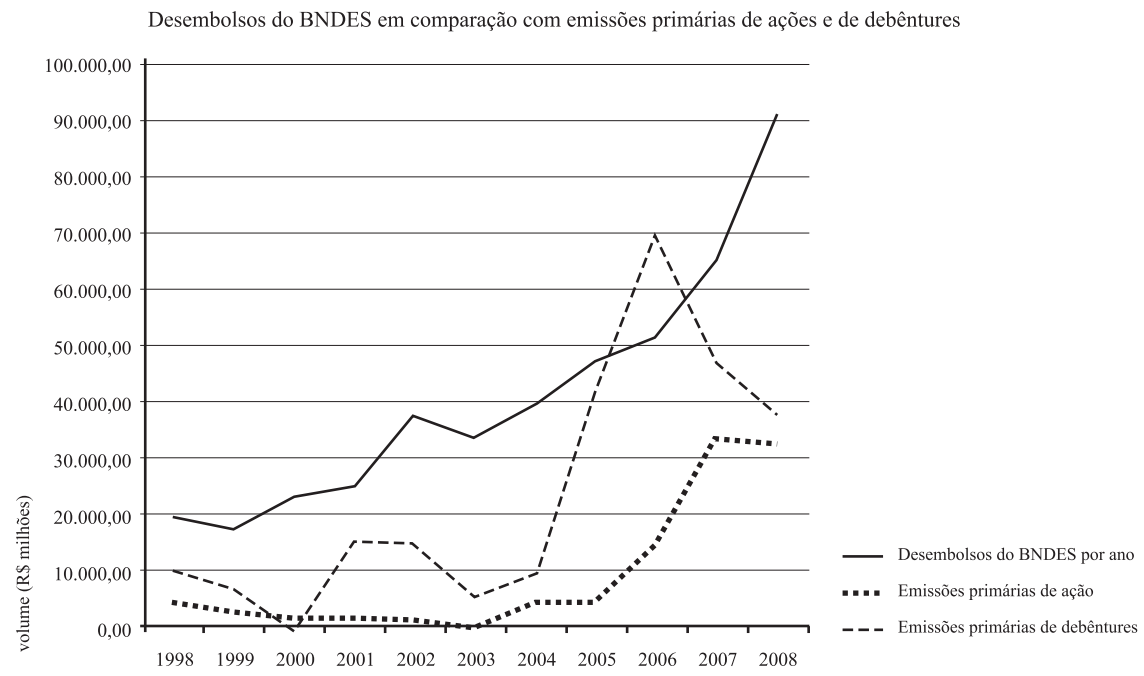

Fonte: BNDES e CVM

Os dados são ainda mais significativos se levarmos em consideração que o BNDES também é um dos maiores agentes financeiros do segmento de valores mobiliários. Como mencionado, desde o II PND, o Banco atua na aquisição de participações em empresas, seja por meio de debêntures, seja por meio de ações. A partir da década de 1990, essa forma de intervenção financeira tem sido crescente, 
tendo apresentado resultados ainda mais robustos nos últimos anos, quando o Banco criou uma área específica para administrar as operações de mercado - Área de Mercado de Capitais (criada em 2005). É ilustrativo desta forma de atuação que, em 2009, o BNDES seja detentor da maior carteira de ações do país, com um valor aproximado de R \$ 60 bilhões. Em número de empresas, somadas a sua participação direta e a sua participação indireta (como cotista de fundos de investimento), o Banco está presente em 306 empresas (listadas ou não) _ ${ }^{21}$ um dado relevante, se se considerar que todo o mercado de capitais conta com 435 empresas listadas.

Essa participação é, de fato, surpreendente, sobretudo para pesquisadores e formuladores de política que tomam o direito como variável de suas análises e proposições. O senso comum partilhado por acadêmicos, advogados empresariais e economistas do direito, influenciados pelo paradigma Rule of Law, é o de que compete às regras jurídicas uma só e mesma função: a definição de um bom ambiente de governança e a estipulação dos meios adequados de proteção dos investidores. Segundo essa leitura, ainda, o Estado é, no mais das vezes, um agente gerador de ineficiência, que impede o desenvolvimento da livre iniciativa: o funcionamento satisfatório dos mercados deve contar, portanto, com regras claras, incentivos corretos e retração da participação do Estado, que de empreendedor deve passar a ser um ator regulador indireto do ambiente financeiro. ${ }^{22}$

O problema desta abordagem, no entanto, é a sua dificuldade em compreender as especificidades institucionais do país, sobretudo em relação à persistente prevalência dos bancos públicos como agentes de financiamento de longo prazo. As reiteradas tentativas de fortalecer o ambiente de mercado, com a promulgação de novas leis e a estipulação de um rol formal de direitos, não têm sido capazes de alterar as características mais significativas do modelo brasileiro de financiamento.

Como se procurará argumentar a seguir, boa parte da divergência entre a compreensão do papel a ser exercido pelo direito e a realidade do panorama financeiro brasileiro deve-se a uma compreensão estreita e estática das funções exercidas pelos arranjos jurídico-institucionais. $\mathrm{Na}$ realidade, as premissas e recomendações da concepção prevalecente, identificada estilizadamente neste trabalho como Rule of Law, parecem preferir os "transplantes" aos "diagnósticos". Em outros termos, têm mais facilidade em identificar e sugerir "boas práticas" do que em compreender as especificidades locais e os correspondentes encadeamentos institucionais. $\mathrm{Na}$ sequência deste trabalho, uma vez apresentados os problemas da concepção prevalecente, o desafio será estabelecer algumas pistas do que pode vir a ser um paradigma alternativo de abordagem de Direito e Desenvolvimento. Uma alternativa que seja capaz de compreender as especificidades do modelo brasileiro e de apresentar um curso de alteração institucional forjado a partir das suas próprias vicissitudes e idiossincrasias. 


\section{Repensando a Relação entre Estado, direito e DesenVolvimento}

A persistência dos agentes estatais no panorama financeiro brasileiro, a despeito dos esforços das reformas econômicas, parece concordar com o diagnóstico de trabalhos recentes, cujas conclusões têm apontado para os limites do Rule of Law, como um paradigma capaz de orientar programas bem-sucedidos de desenvolvimento econômico (TAMANAHA, 2009). Após a década de 1990, alguns pesquisadores e policy makers passaram a chamar a atenção a que a adoção das "instituições corretas", pelos países latino-americanos, do Leste Europeu e da África Subsaariana, não havia sido suficiente para conduzir as suas economias a patamares satisfatórios de crescimento e distribuição de renda, revelando, em muitos casos, um desempenho menos expressivo do que o apresentado por alguns países asiáticos, como a Coreia do Sul e a China, que trilharam um caminho institucional heterodoxo (SABEL, 2005, p. 4). Entre essas experiências, o panorama financeiro brasileiro é mais um caso, que reforça dois problemas críticos da agenda contemporânea de Direito e Desenvolvimento: (i) uma concepção demasiadamente estreita do papel do direito, tomado meramente como uma ferramenta de proteção a agentes privados e (ii) uma confiança exagerada no potencial das reformas jurídico-institucionais, das quais se esperava a capacidade de, por meio de leis e regulamentos formais, alterar substantivamente os atributos materiais, historicamente forjados, dos arranjos nacionais.

Com relação ao papel do direito, notadamente no ambiente financeiro, Milhaupt e Pistor (2008) sugerem que o paradigma prevalecente toma as regras jurídicas apenas e tão somente como instrumentos de proteção de agentes pulverizados em mercado e, com isso, ignora a existência de outras alternativas institucionais, as quais demandam do direito um elenco diversificado de atribuições. Para além da função de proteção individual dos interesses, as ferramentas jurídicas podem também ter outros papéis, como, por exemplo, o de garantir uma coordenação coletiva dos agentes econômicos ou até mesmo permitir a organização de um sistema financeiro público.

A função de coordenação coletiva, em detrimento da valorização da proteção individual, pode ser constatada em regras de governança corporativa que, em vez de privilegiarem a defesa de acionistas atomizados, estimulam as negociações entre grupos de interesse internos às companhias, como as existentes entre os administradores e os acionistas com participação em bloco, um traço típico da regulação societária alemã (PISTOR, 2005). Outro exemplo possível são as regras jurídicas, também do regime societário alemão, segundo as quais trabalhadores e acionistas são igualmente representados no conselho de administração e estimulados a empreender processos de negociação coletiva, dos quais resultam as estratégias corporativas. Em ambos os casos (negociações com acionistas em bloco e com trabalhadores), o papel principal do direito societário não é oferecer mecanismos para uma proteção individualizada da propriedade, seja de acionistas ou de credores, realizada na forma de uma litigância personalista, mas sim garantir, por meio de regras de governança, 
espaços e instrumentos que estimulem barganhas entre grupos corporativos, resultando assim na representação dos interesses dos diversos stakeholders.

Da mesma forma, nas economias em desenvolvimento, pode-se constatar uma participação mais expressiva de empresas estatais e bancos públicos, o que revela um outro papel para o direito: o de constituir um sistema financeiro público no qual os agentes estatais é que estabelecem as mediações entre poupadores e investidores, valendo-se para tanto dos dispositivos de poupança compulsória e do direcionamento estatal dos recursos. Em última análise, a percepção de que o direito pode exercer papéis diversificados na organização de um sistema financeiro, para além da proteção da propriedade privada dos investidores, revela que a noção de "instituições corretas” é, enfim, bastante restritiva. Afinal de contas, são corretas de acordo com qual desses modelos?

$\mathrm{Na}$ realidade, há que se ter em conta que o direito desempenha um elenco variado de papéis, que extrapola a garantia da ordem e a proteção dos indivíduos, isto é, funções meramente regulatórias. A seguinte passagem de Tamanaha (1995) a esse respeito parece concordar com as análises de Milhaupt e Pistor (2008) e relembra os pesquisadores e policy makers de que o direito não é a única instância de organização social e tampouco exerce uma única função no ambiente social. A rigor, a pluralidade de papéis desempenhados pelo direito, imersa em um ambiente social composto por outras ordens normativas, como são os padrões culturais e os atributos comportamentais, conforma, nos ambientes nacionais, uma possibilidade variada de desenhos jurídico-institucionais:

Law (at least state law) performs many functions besides social control, including, inter alia, enabling or facilitative, performative, status conferring, defining, legitimative, integrative, distributive, power conferring, and symbolic; and there are many forms of social control besides law. For various reason we have often lost sight of both halves of this non-identity. (TAMANAHA, 1995, p. 519)

A segunda questão suscitada pelo paradigma Rule of Law é a ambição exagerada dos programas de reforma institucional. As expectativa desses programas são de que (i) as alterações no panorama jurídico seriam plenamente realizáveis e de que (ii) essas alterações bastariam para conduzir os países a novos patamares de desenvolvimento. Trebilcock e Prado (2009), todavia, ao apresentarem um balanço da literatura sobre instituições e desenvolvimento nos últimos anos, indicam a crescente percepção de desapontamento quanto aos resultados alcançados, após um período de euforia em relação às possibilidades de difusão das "instituições corretas". Para os autores, uma possível explicação dos limites encontrados pelas diversas iniciativas de reformas é a resistência oferecida pela inércia institucional, isto é, a dificuldade encontrada em alterar um arranjo previamente estruturado, em função dos custos e 
dos interesses envolvidos - o argumento da path dependence (dependência da trajetória institucional pregressa). Seja em função dos obstáculos oferecidos pelos grupos de interesse, porventura contrários a modificações nas regras do jogo, seja pelo fato de que as regras formais não são capazes per se de alterar hábitos e procedimentos culturalmente constituídos, o fato é que a adoção formal de novas leis e dispositivos jurídicos pode não ser nem trivial, nem suficiente. A dinâmica dos arranjos institucionais, em suma, tende a ser dependente da sua trajetória pregressa, de forma que as alterações abruptas são menos prováveis que as acomodações incrementais.

No campo financeiro, estes dois problemas - a concepção estreita do direito e a ambição dos programas de reforma - podem ser encontrados nas análises e recomendações de política que compõem a literatura Law and Finance. Os estudos cross-country e os seus desdobramentos normativos se alimentam de um elenco de direitos afinados com uma alternativa institucional bem definida, na qual prevalecem as transações financeiras atomizadas e descontinuadas. Respostas institucionais diversificadas são compreendidas, pelos autores e policy makers, como desvios de um padrão "correto" de organização institucional. Este é o caso, por exemplo, da interpretação oferecida por La Porta et al. (2000a) para o papel dos bancos públicos nos países asiáticos, que garantiram patamares elevados de disponibilidade de crédito nessas economias: os bancos públicos não são entendidos como resultado de um arranjo nacional, mas sim como uma patologia, um produto das falhas existentes na proteção jurídica dos investidores privados desses países. O desdobramento político desse enfoque tem balizado reformas financeiras como a conduzida no ambiente financeiro brasileiro, cujas medidas foram baseadas, como visto, no diagnóstico de que as lacunas institucionais é que representam um obstáculo ao florescimento do mercado de capitais no país. A garantia de boas leis e regras de governança satisfatórias seriam, portanto, veículos de propagação de um arranjo financeiro desenvolvido, baseado no mercado e nas atuações de poupadores individuais.

Diferentemente de tal concepção, ainda prevalecente, alguns trabalhos recentes têm procurado uma compreensão do direito e das instituições que ultrapassa os limites formais, ou seja, eles assumem que o ambiente das regras jurídicas não é descolado do restante do entorno institucional. Autores como Hall e Soskice (2001), Rodrik (2001), Sabel (2004), Milhaupt e Pistor (2008) e Tamanaha (2009), entre outros, têm procurado uma abordagem heterodoxa das relações existentes entre os arranjos institucionais e os resultados econômicos. Nesta chave, a relação entre direito e desenvolvimento não é tomada de modo formal e, menos ainda, de maneira unidirecional, o que levaria a supor, aos moldes do Rule of Law, que a mera existência das regras formais "corretas" ensejaria por si só bons resultados de desenvolvimento. Diferentemente disso, esses autores têm procurado um alargamento da concepção de direito e das instituições, para além da função de proteção e provisão de segurança jurídica, e têm apresentado também uma reorientação do 
vetor das reformas institucionais. Mais ainda, eles compreendem que os diferentes sistemas regulatórios, regras, padrões culturais e valores fundamentais formadores de um arranjo institucional constituem entre si um encadeamento que reforça as características de funcionamento dos modelos (HALL; SOSKICE, 2001, pp. 1-68). É em razão desta diversidade dos arranjos nacionais e da dinâmica de seus encadeamentos locais que as funções exercidas pelo direito extrapolam as da concepção prevalecente e é também por este motivo que as recomendações de reforma de viés one size fits all apresentam o seu teor de frustração.

Nessa abordagem, que pode ser identificada como paradigma das alternativas institucionais, assume-se igualmente o pressuposto de que há uma correlação positiva entre o desenho de arranjos jurídico-institucionais e o alcance de bons indicadores de produtividade, crescimento e renda, mas parte-se da premissa de que esses desenhos devem ter como ponto de partida a trama social dada, concentrando-se em uma reprogramação da trajetória institucional existente. A noção de alternativas institucionais tem em conta que as economias de mercado, muito embora detenham traços comuns como a garantia da propriedade privada e a persecução do lucro nas transações comerciais, não apresentam uma conformação idêntica - um padrão único. Ao contrário, a articulação entre os grupos de interesse, o modo de funcionamento dos mercados, a forma de organização do sistema jurídico, os valores sócio-culturais prevalecentes, entre outros, conforma diferentes possibilidades institucionais de regimes econômicos e sistemas sociais (HALL; SOSKICE, 2001, pp. 1-68). Por esta razão, as reformas tendem a ser melhor sucedidas à medida que os policy makers forem capazes de reconhecer os encadeamentos locais e, a partir deles, estabelecer um arcabouço de regras e práticas. É o que salienta Tamanaha (2009):

The results of reform efforts depend upon how they interact with the surrounding complex of factors - the connectedness of law principle - and this can lead in any direction. It depends upon cultural views; it depends upon the personal incentives at play (who stands to gain or lose money, status, or power); and it depends upon many other factors. There is no doubt that rule of law, democracy, civil rights, and social welfare capitalism can exist in a mutually supporting fashion, as they do in liberal democracies. Nothing inherent to the rule of law, however, leads to the replication of this arrangement in the countries that are the targets of law and development projects, which have vastly different social-cultural-economic-political-legal dynamics. (p. 26)

É isso que mostram os casos de sucesso discutidos por Dani Rodrik, no livro In Search of Prosperity (2001) e por Charles Sabel, em Bootstraping Development (2005). Em sintonia com as avaliações de Tamanaha, ambos os autores têm argumentado que as políticas de desenvolvimento bem-sucedidas, empreendidas por países tão diferentes 
como Botsuana, Brasil e Chile, têm se valido de uma estratégia de intervenção baseada no aprendizado, no processamento e na reação do próprio arranjo institucional. Isto é, em vez de aderirem a um pacote pré-moldado de regras e desenhos institucionais, as políticas exitosas têm se valido de uma espécie de autoalavancagem (bootstrapping) institucional. Trata-se, portanto, de uma compreensão que toma a relação entre direito e desenvolvimento em uma dupla e conjugada perspectiva: (i) a da oferta de instituições positivas (perspectiva top down) e (ii) a da demanda forjada localmente (perspectiva bottom up) (MILHAUPT; PISTOR, 2008, pp. 40-44).

O ponto de partida deste enquadramento alternativo das medidas de reconfiguração institucional é o diagnóstico das especificidades e da dinâmica de funcionamento dos ambientes e dos arranjos, e o ponto de chegada é a reprogramação deste conjunto sem, no entanto, investir na sua descaracterização. Isso pressupõe tomar o direito não como uma dotação de fatores (endowment), capaz de ser transplantável de um arranjo a outro, mas como um atributo institucional socialmente incrustrado (embedded). Também significa admitir que as suas funções são diferentes, conforme o tipo de alternativa institucional, e impõe, por último, uma expectativa distinta com relação ao papel das reformas: menos voltadas às "adoções" e mais atentas às "gerações".

Quadro 2 - Modelos de Direito e desenvolvimento

\begin{tabular}{|c|c|c|}
\hline & PARADIGMA RULE OF LAW & PARADIGMA DAS ALTERNATIVAS INSTITUCIONAIS \\
\hline $\begin{array}{l}\text { CONCEPÇÃO } \\
\text { DE DIREITO }\end{array}$ & $\begin{array}{l}\text { DIREITO COMO UMA DOTAÇÃO DE FATORES } \\
\text { (ENDOWMENT) }\end{array}$ & $\begin{array}{l}\text { DIREITO COMO UM ATRIBUTO ASSOCIADO } \\
\text { AO ARRANJO INSTITUCIONAL (EMBEDDED) }\end{array}$ \\
\hline $\begin{array}{l}\text { FUNÇÃO DO } \\
\text { DIREITO }\end{array}$ & PROTEÇÃO DE AGENTES PRIVADOS & $\begin{array}{l}\text { ARIÁVEL CONFORME O TIPO DE ORGANIZAÇÃO } \\
\text { INSTITUCIONAL }\end{array}$ \\
\hline $\begin{array}{r}\text { PAPEL DAS } \\
\text { REFORMAS } \\
\text { INSTITUCIONAIS }\end{array}$ & $\begin{array}{l}\text { QUALIFICAR INSTITUIÇÕES LOCAIS A } \\
\text { PARTIR DA OFERTA DE INSTITUIÇÕES } \\
\text { "CORRETAS" }\end{array}$ & $\begin{array}{l}\text { QUALIFICAR INSTITUIČ̃̃ES LOCAIS A PARTIR DE } \\
\text { SUA REPROGRAMAÇÃO - APRENDIZADO, } \\
\text { PROCESSAMENTO É REAÇÃOO }\end{array}$ \\
\hline
\end{tabular}

No panorama brasileiro, a trajetória do BNDES, para além de desafiar as expectativas das reformas econômicas conduzidas aos moldes do Rule of Law, tem sido também um exemplo significativo do que pode ser um exercício de reprogramação institucional. Embora o Banco tenha sido constituído como um agente de apoio aos programas desenvolvimentistas, adequado ao padrão de desenvolvimento Estadocentrado e às estratégias substitutivas de importação, sua intervenção tem sido redesenhada nos últimos vinte anos. De um ator encarregado das metas inscritas nos planos governamentais de desenvolvimento, o BNDES passou a ser um agente relevante para o mercado de capitais e para as estratégias corporativas afinadas com uma economia internacionalizada. 
Essa alteração de curso é particularmente visível na estipulação de novos veículos de financiamento, boa parte dos quais baseada em transações com valores mobiliários e parcerias com os demais agentes de mercado. Valendo-se de uma racionalidade bastante diferente da que balizou a sua intervenção entre 1950 e 1980, o BNDES tem atuado em convergência com os demais atores financeiros, e o resultado de sua ação não só tem garantido recursos para as empresas como também tem permitido um adensamento do mercado de capitais no país (SCHAPIRO, 2009). De um lado, o Banco tem estimulado as empresas de seu portfolio a incorporarem regras de governança e, tão logo seja possível, a atuar no ambiente de mercado; um exemplo disso são os investimentos de private equity em empresas como Lupatech S.A., Bematech S.A. e TOTVS S.A., que após um período de maturação realizaram a abertura de seu capital no Novo Mercado da Bovespa. De outro lado, o Banco tem desempenhado um papel de indutor indireto do mercado de capitais, ao atuar em parceria com fundos de investimento e investidores privados.

O destino das participações societárias realizadas diretamente pelo Banco tem coberto desde as empresas emergentes, com potencial de gerar inovações de processo e de produto, até grandes empresas, capacitadas a empreender estratégias de internacionalização. No segmento de empresas emergentes, a carteira de investimentos é composta por cerca de quarenta empresas, de setores que incluem Tecnologia da Informação, Biotecnologia, Química e Alimentos. Os investimentos em grandes empresas, por sua vez, têm favorecido os setores de Mineração, Alimentos, Tecnologia da Informação e Frigoríficos, em uma carteira com aproximadamente 185 empresas (COUTINHO, 2008). ${ }^{23}$ Entre 2006 e 2007, foram realizadas 56 operações societárias com grandes empresas, contabilizando um montante da ordem de R $\$ 7$ bilhões (BNDES, 2007). Nesse período, uma operação particularmente relevante e que evidencia uma estratégia de intervenção em novos patamares foi a capitalização do frigorífico JBS: por meio de um aporte de recursos da ordem de R \$ 1 bilhão, estruturado na forma de subscrição de ações, o Banco apoiou a estratégia de internacionalização da empresa, que procurou ingressar no mercado norte-americano (BNDES, 2007).

No caso dos fundos, o BNDES tem atuado como cotista de fundos privados, participando de um montante de 24 fundos de private equity e de 14 fundos de venture capital, dedicados a empresas emergentes (BNDES, 2007). Neste último segmento, trata-se de uma participação expressiva, se se considerar que há 28 fundos de venture capital registrados na CVM (fundos sujeitos à Instrução Normativa $n^{\circ} 209$ ). Essas atuações têm sido, ainda, acompanhadas de iniciativas de fomento institucional, como, por exemplo, a participação do BNDES no IPO da Nutriplant, empresa que abriu o capital no mercado de acesso da Bovespa - o Bovespa Mais. Até agora, essa foi a única operação de abertura de capital registrada neste segmento do mercado de capitais, destinado a empresas menores, como são as empresas emergentes e de base 
tecnológica. A intervenção do Banco, ocorrida no momento do IPO, ou seja, em uma ocasião em que a empresa não necessitaria mais de seus recursos públicos, teve na verdade a finalidade de contribuir para o desbravamento do Bovespa Mais (SCHAPIRO, 2009). Tratou-se, enfim, de uma atuação do Banco dirigida a apoiar o mercado de capitais. ${ }^{24}$

A experiência recente do BNDES no segmento de valores mobiliários, tanto nas operações diretas como nas indiretas, é um exemplo significativo de que o reconhecimento das especificidades das alternativas pode permitir reprogramações institucionais bem-sucedidas. Esta trajetória indica que, partindo-se de um redesenho da propriedade estatal, em vez de apostar apenas na incorporação de um novo arranjo jurídico-institucional, podem-se obter resultados satisfatórios para as estratégias de desenvolvimento. No caso do BNDES em particular, a sua atuação no mercado de capitais tem contribuído para o desenvolvimento das operações com renda variável, garantindo assim um incremento das fontes de financiamento disponíveis na economia brasileira. Em suma, a compreensão de que o modelo brasileiro conta com agentes estatais com uma dimensão expressiva, se encarada como uma idiossincrasia local e não como um defeito, pode, enfim, permitir intervenções eficazes e portadoras de menores resistências.

\section{Conclusão}

Passados quase vinte anos do apogeu do propalado Consenso de Washington, a literatura de Direito e desenvolvimento tem sido incrementada por um bom número de produções de caráter heterodoxo. Em relação aos estudos do início da década passada, as pesquisas recentes têm procurado sugerir que as réguas e métricas que embalaram os primeiros desenhos das reformas institucionais são bastante estreitas, quando não divorciadas do funcionamento real dos ambientes nacionais. Em razão disso, concepções como as do Law and Finance, que tomam o Direito como uma dotação de fatores, isto é, como uma pré-condição rígida do desenvolvimento, têm enfrentado uma paulatina resistência, teórica e também de formuladores de política pública. Talvez por esta razão, ao longo da década de 2000, tenha ganhado projeção a produção de autores dedicados a refutar as fórmulas institucionais standard, baseados na percepção de que os arranjos nacionais comportam uma variedade de modelos e as indicações de caráter one size fits all tendem a ser tão sedutoras quanto potencialmente ineficazes.

Nesse panorama, um exemplo típico que confirma tais apontamentos é o do sistema financeiro brasileiro. Desde a etapa industrial, o financiamento de longo prazo do país tem sido incumbido aos bancos estatais. O mercado de capitais e os bancos privados desempenharam um papel residual e, mesmo em tempos recentes, em que se assistiu a um incremento das operações na bolsa e a uma internacionalização do 
mercado bancário, os bancos públicos, e o BNDES em particular, têm continuado a desempenhar um papel-chave. Esta constatação pode gerar dois tipos de reação, cada qual afinada com um paradigma de Direito e desenvolvimento: (i) a primeira delas, aos moldes Rule of Law, é a de apontar os defeitos desse arranjo, excessivamente Estado-centrado, e apostar em novas e sucessivas rodadas de reformas financeiras dedicadas a ampliar a proteção privada e assim incentivar o funcionamento dos mercados; (ii) a segunda reação possível é pragmática, consiste em uma compreensão das vicissitudes do arranjo nacional e opta por um incremento institucional a partir dos encadeamentos locais - no caso concreto, isso significa utilizar o BNDES para induzir o mercado de capitais nacional e, consequentemente, o conjunto do mercado financeiro. Boa parte da literatura recente de Direito e desenvolvimento e a dinâmica do sistema financeiro nacional parecem corroborar a segunda opção.

Este segundo caminho impõe, no entanto, sobretudo para formuladores de política e pesquisadores de países em desenvolvimento, o difícil desafio de imaginar o futuro dos ambientes institucionais aceitando, em primeiro lugar, sua efetiva realidade. Isso pressupõe se desfazer dos recalques e dos impulsos à imitação das "boas práticas" e "instituições corretas". Demanda ainda alguma criatividade e, mais que tudo, uma abertura para o experimentalismo institucional.

: ARTIGO APROVADO (10/06/2010) : RECEBIDO EM 24/08/2009

NOTAS

1 Uma primeira versão deste trabalho foi discutida no workshop de pesquisa da DIREITO GV, tendo sido encaminhada para futura publicação no livro Estado de Direito e Desenvolvimento, coordenado por Oscar Vilhena Vieira. Pelas observações e críticas feitas naquela ocasião, agradeço aos colegas presentes, notadamente a José Rodrigo Rodriguez e Bruno Meyerhof Salama. A Silas Cardoso de Souza, agradeço pela primeira revisão; a Helena Cavalcanti, agradeço pela cuidadosa leitura e pela revisão final; e a Mariana Giorgetti Valente, pela ajuda na elaboração dos gráficos. As pessoas citadas não têm qualquer responsabilidade por este trabalho.

2 Esta comparação feita por Danino é apresentada por Brian Tamanaha em The Primacy of Society and the Failures of Law and Development.

3 Nesse sentido, há uma diferença importante entre o tratamento conferido às instituições pelos novos economistas institucionais e a abordagem do antigo institucionalismo e da sociologia econômica. Enquanto a NEI toma as instituições como externas ao mercado, os sociólogos e antigos institucionalistas concebem-nas como atributos socialmente construídos - são incrustrados na estrutura social (embedded). Os tipos de regras ou as formas contratuais são pré-existentes e difusos na ordem social - são os chamados elementos pré-contratuais do contrato. Para uma síntese a esse respeito, ver: Granovetter, Mark, Economic Action and Social Structure: The Problem of Embeddedness, The American Journal of Sociology, v. 91, n. 3, 1985. 
4 Para uma crítica desta abordagem que caracteriza estes programas de desenvolvimento, desconectados do primado da sociedade, ver: The Primacy of Society and the Failures of Law and Development, de Brian Tamanaha (2009, pp. 1-10).

5 Alguns dos principais trabalhos são: La Porta, et al. (1998); La Porta, et al. (1997); Shleifer e Vishny (1997); La Porta, et al. (2000a); Beck, Demirgürç-Kunt e Levine (2001); Beck e Levine (2004).

6 O projeto Doing Business foi iniciado em 2003 e tem o propósito de avaliar o ambiente de negócios dos países membros do Banco. O padrão de avaliação dos ambientes financeiros nacionais, em particular, segue os parâmetros dos estudos Law and Finance, assim como as reformas institucionais apoiadas pelo Banco Mundial assumem os critérios e a concepção de direito que embasa os estudos dos autores associados a esta linha de pesquisa. A proteção dos direitos de propriedade dos investidores e a capacidade de enforcement dos contratos, temas bastante frequentes nos estudos Law and Finance, figuram como elementos relevantes dos rankings estabelecidos pelo Banco Mundial no âmbito do Doing Business Project. Para outras informações a respeito, ver: Milhaupt e Pistor, Law and Capitalism - What Corporate Crises Reveal About Legal Systems and Economic Development Around the World (Chigaco: Chicago Press, 2008) e Fabiani, Reformas Institucionais do Mercado de Crédito Bancário no Brasil (1999-2006) - uma análise jus-sociológica (Tese de Doutorado Faculdade de Direito, Universidade de São Paulo, São Paulo, 2009).

7 A esse respeito salientam La Porta et al. (2000a): “At the extreme of no investor protection, the insiders can steal a firm's profits perfectly efficiently. Without a strong reputation, no rational outsider would finance such a firm. As investor protection improves, the insider must engage in more distorted and wasteful diversion practices such as setting up intermediary companies into which they channel profits. Yet these mechanisms are still efficient enough for the insiders to choose to divert extensively. When investor protections is very good, the most the insiders can do is overpay themselves, put relatives in management, and undertake some wasteful projects. After a point, it may be better just pay dividends. As the diversion technology becomes less efficient, the insiders expropriate less and their privet benefits of control diminish. Firms then obtain outside finance on better terms. By shaping the expropriation technology, the law also shapes the opportunities for external finance" (p. 6).

8 O rol é composto pelos seguintes direitos: (i) garantia dos acionistas - (1) possibilidade de votação não presencial (possibilidade de voto pelo correio, por exemplo); (2) possibilidade de negociar ações a qualquer tempo (inexigência de depósito prévio das ações, preliminarmente aos encontros de acionistas); (3) existência de voto proporcional para garantir os interesses dos minoritários; (4) proteção aos acionistas dissidentes (recompra de ações ou possibilidade de questionamentos da política corporativa); (5) preferência na aquisição de novas ações; (6) possibilidade de convocação do encontro de acionistas, ainda que com uma participação não expressiva no capital social -; (ii) garantia dos credores - (1) previsão do direito de posse sobre a garantia prestada, independente dos processos de reorganização societária; (2) concessão do direito de preferência à retenção das garantias aos seus titulares nos processos de reorganização; (3) previsão de anuência prévia dos credores para a recuperação da empresa devedora; (4) possibilidade de substituir os administradores durante a reorganização das empresas (LA PORTA et al., 1998).

9 Para justificar a sua classificação, os autores argumentam que as famílias apresentam origens distintas, o que impactou também a sua evolução. Tais famílias teriam ainda se difundidas para outros países, às custas dos processos de transplante institucional. Assim, enquanto o sistema francês teria resultado de um movimento revolucionário bastante contrário aos privilégios da magistratura e também das intenções codificadoras de Napoleão, o sistema inglês teria na sua origem a preponderância das Cortes em relação à Monarquia. A consequência dessas diferenças seria perceptível no enrijecimento do sistema francês, que teria apostado no modelo jurisdicional do juiz limitado pela codificação estrita - o "juiz boca da lei" -, ao passo que no modelo inglês a primazia dos Tribunais teria garantido um sistema mais flexível, baseado na construção do direito pelos casos julgados. Nessa toada, o sistema alemão, embora de origem civil law, é apresentado como um tipo próprio. Como a sua codificação teria sido formulada de modo a favorecer a incorporação de princípios, este sistema gozaria de maior maleabilidade para responder aos imperativos econômicos. Por fim, o sistema escandinavo surge como um outro gênero, identificado pelo seu menor grau de parentesco com a tradição do direito romano de Justiniano, entendido como uma herança tendente a mitigar o papel da jurisprudência em favor da positivação de leis e códigos. Os países pesquisados de cada família são os seguintes: (i) Common Law: Inglaterra, Estados Unidos, Canadá, Hong Kong, Irlanda e Israel; (ii) Civil Law Francesa: França, Brasil, Chile, Colômbia, Egito e Espanha; (iii) Civil Law Germânica: Alemanha, Áustria, Japão, Coreia do Sul, Suíça e Taiwan; (iv) Sistema Escandinavo: Dinamarca, Finlândia, Noruega e Suécia. Ver, a esse respeito, La Porta et al., Law and Finance, Journal of Political Economy, v. 106, n. 6, 1998; e Beck e Levine, Legal Institutions and Financial Development, Working Paper 10.417, National Bureau of Economic Research, 2004.

10 Nos países de common law, por exemplo, 39\% dos ordenamentos nacionais admitem o voto pelo correio, ao passo que apenas $5 \%$ dos sistemas jurídicos de civil law de origem francesa franqueiam esta possibilidade aos acionistas - um 
direito entendido pelos autores como um facilitador da representação corporativa de acionistas minoritários (LA PORTA et al., 1998).

11 O lucro líquido anual do BNDES em 2007 foi de R \$ 7,3 bilhões, e em 2008, de R \$ 5,3 bilhões. São dados expressivos, se se tiver em conta os valores apresentados pelo Bradesco, um dos maiores bancos privados do país. Em 2007, o lucro do Bradesco atingiu aproximadamente R\$ 8 bilhões, e em 2008, R\$ 7,6 bilhões. Ver a respeito: <http://www.bndes.gov.br/SiteBNDES/bndes/bndes_pt/Institucional/Relacao_Com_Investidores/Desempenho/> e http://www1.folha.uol.com.br/folha/dinheiro/ult91u497246.shtml. Acesso em: 15 jul 2009.

12 Este dado é apresentado no gráfico 2.

13 Para um survey dos bancos públicos e a sua preponderância em países em desenvolvimento, ver: NOVAES, Intermediação Financeira, Bancos Estatais e o Mercado de Capitais: a experiência internacional, em PINHEIRO; OLIVEIRA FILHO (orgs.), Mercado de Capitais e Bancos Públicos - análise e experiências comparadas (Rio de Janeiro; São Paulo: Contra Capa; ANBID, 2007).

14 Daqui em diante será utilizada a sigla atual do Banco - BNDES.

15 Sobre as alterações institucionais ocorridas no setor financeiro nacional, ver: Cintra, A reestruturação patrimonial do sistema bancário brasileiro e os ciclos de crédito entre 1995 e 2005. In: CARNEIRO. A Supremacia dos Mercados - e a política econômica do Governo Lula (São Paulo: UNESP, 2006); e Stalling e Studart, Finance for Development - Latin America in Comparative Perspective (Washington: Brookings Institution Press, 2006).

16 Dados do Banco Central do Brasil. Disponível em: <www.bcb.gov.br>. Acesso em: 05 jul. 2009.

17 A série de trabalhos mencionada no excerto é composta, segundo o texto da MB Associados, por: La Porta et al. (1997, 1998, 1999).

18 Estas regras podem ser obtidas em: <www.bovespa.com.br>.

19 Dados do Banco Central do Brasil. Disponível em: <www.bcb.gov.br>. Acesso em: 05 jul. 2009.

20 Diz o texto da Constituição: “Art. 239. A arrecadação decorrente das contribuições para o Programa de Integração Social, criado pela Lei Complementar $n^{\circ} 7$, de 7 de setembro de 1970, e para o Programa de Formação do Patrimônio do Servidor Público, criado pela Lei Complementar no 8, de 3 de dezembro de 1970, passa, a partir da promulgação desta Constituição, a financiar, nos termos que a lei dispuser, o programa do seguro-desemprego e o abono de que trata o $\S 3^{\circ}$ deste artigo. (Regulamento) $\S 1^{\circ}$ - Dos recursos mencionados no "caput" deste artigo, pelo menos quarenta por cento serão destinados a financiar programas de desenvolvimento econômico, através do Banco Nacional de Desenvolvimento Econômico e Social, com critérios de remuneração que lhes preservem o valor. Constituição da República Federativa do Brasil”. Para uma explicação acerca do funcionamento deste fundo, ver: ARIDA, Mecanismos compulsórios e mercados de capitais: propostas de política econômica, Texto para Discussão, Instituto Casa das Garças, $\mathrm{n}$. 8, 2005. Disponível em: <http://iepecdg.com/DISK\%201/Arquivos/TPD/TPD8IEPE.pdf>.

21 Dados apresentados pela matéria de capa do jornal Valor Econômico, edição de 25 de março de 2009.

22 Esta abordagem é bastante recorrente. Para citar apenas um exemplo, assinala o relatório da MB Associados (2000): “[...] portanto, é fundamental a criação e o incentivo a mecanismos formais de poupança doméstica - que se baseiem no funcionamento livre dos mercados - para impulsionar o desenvolvimento e diminuir a dependência do capital externo. No passado o governo lançou mão de mecanismos oficiais e compulsórios de poupança. Esse tipo de recursos esgotou-se e a tendência é que o Estado se limite a regular mecanismos voluntários de acumulação de capitais" (p. 17).

23 Dados de setembro de 2008 .

24 Foi este o tom do noticiário especializado. Em matéria do dia 20 de junho de 2008, a Gazeta Mercantil apresentava a possibilidade de o Banco repetir a operação da Nutriplant com outras empresas, como a Teikon e BRQ. Na matéria intitulada "BNDES pode alavancar lista do Bovespa Mais", constava a seguinte descrição: "O BNDESpar pode ser, indiretamente, o grande alavancador da Bovespa Mais, o segmento da bolsa paulista destinado às empresas de menor porte 
que querem acessar o mercado de capitais. Na reunião com cerca de 200 analistas, investidores e consultores ontem na Bovespa, as interessadas na listagem Teikon e BRQ apresentaram expectativas e atuações distintas - mas com um fator comum. As duas empresas tiveram alavancagem com a entrada do BNDES na estrutura acionária, geralmente como debenturista, tomando fôlego para estudar o mercado de capitais. O banco de desenvolvimento também detém 10,79\% da Nutriplant, a única empresa listada na Bovespa Mais".

\section{REFERÊNCIAS BIBLIOGRÁFICAS}

ARIDA, Pérsio. Mecanismos compulsórios e mercados de capitais: propostas de política econômica. Texto para Discussão, Instituto Casa das Garças, n. 8, 2005. Disponível em:

<http: / /iepecdg.com/DISK\%201/Arquivos/TPD/TPD8IEPE.pdf>.

BAUMOL, William; PANZER, J.; WILLIG, D. Contestable Markets and the Theory of Industrial Structure. Nova Iorque: Harcourt Brace Jovanovich, 1982.

BECK, Thorsten; LEVINE, Ross. Legal Institutions and Financial Development. Working Paper 10.417, National Bureau of Economic Research, 2004.

BECK, Thorsten; DEMIRGÜÇ-KUNT, Asli; LEVINE, Ross. Law, Politics and Finance. Paper disponível em: $<$ http://papers.ssrn.com/sol3/papers.cfm?abstract_id=269118>.

BANCO NACIONAL DE DESENVOLVIMENTO ECONÔMICO E SOCIAL (BNDES). Relatório Anual de 2007. Disponível em <http://www.bndes.gov.br/SiteBNDES/bndes/bndes_pt/Institucional/Relacao_Com_Investidores/ Relatorio_Anual/RelAnual2007.html>.

BRESSER PEREIRA, Luiz Carlos. Reforma do Estado nos Anos 90 - lógica e mecanismos de controle. Lua Nova Revista de Cultura e Política, n. 45, 1998.

CHANG, Ha Joon. The Economics and Politics of Regulation. Cambridge Journal of Economics, n. 21, 1997. The Poltical Economy of Industrial Policy, Nova Iorque: St. Martins's Press, 1994

CHANG, Ha Joon; EVANS, Peter. The Role of Institutions in Economic Change. In: OTHER CANONS, 2000, Oslo. Paper... Oslo, 2000 .

CINTRA, Marcos Antonio Macedo. A reestruturação patrimonial do sistema bancário brasileiro e os ciclos de crédito entre 1995 e 2005. In: CARNEIRO, Ricardo. A Supremacia dos Mercados - e a política econômica do Governo Lula. São Paulo: UNESP, 2006.

COUTINHO, Luciano. BNDES: Desempenho 2008 e Perspectivas 2009. Apresentações da alta administração do BNDES, 2009. Disponível em: <http://www.bndes.gov.br/empresa/apresentacoes.asp >.

COUTINHO, Luciano; REICHSTUL, Henri-Philippe. O Setor Produtivo Estatal e o Ciclo. Em MARTINS, Carlos Estevam (org.). Estado e Capitalismo no Brasil. São Paulo: Hucitec; CEBRAP, 1977.

CURRALERO, Claudia Regina Baddini. A Atuação do Sistema BNDES como Instituição Financeira de Fomento no Período 1952-1996. 1998. Dissertação (Mestrado) - Instituto de Economia, Universidade de Campinas, Campinas, 1998. DAM, Kenneth. The Law-Growth Nexus - the rule of law and economic development. Washington: Brookings Institution Press, 2006.

DE SOTO, Hernando. The Mystery of Capital: Why Capitalism Triumphs in the West and Fails Everywhere Else. Nova Iorque: Basic Books, 2000.

DEMSETZ, Harold. Why Regulate Utilities. Journal of Law and Economics, v. 11, 1968.

EVANS, Peter. Challenges of the "Institutional Turn". In: NEE, Victor; SWEDBERG, Richard. The Economic Sociology of Capitalism. Nova Jersey: Princeton Press, 2005.

FABIANI, Emerson. Reformas Institucionais do Mercado de Crédito Bancário no Brasil (1999-2006) - uma análise jussociológica. 2009. Tese (Doutorado) - Faculdade de Direito, Universidade de São Paulo, São Paulo, 2009.

GRANOVETTER, Mark. Economic Action and Social Structure: The Problem of Embeddedness. The American Journal of Sociology, v. 91, n. 3, 1985.

HALL, Peter; SOSKICE, David. Introduction. In: HALL, Peter; SOSKICE, David.Varieties of Capitalism - the Institutional Foundations of Comparative Advantage. Nova Iorque: Oxford Press, 2001.

KENNEDY, David. The "Rule of Law", Political Choices, and Development Common Sense. Em TRUBEK, David; SANTOS, Alvaro. The New Law and Development - a Critical Appraisal. Nova Iorque: Cambridge, 2006.

LA PORTA, Rafael; LOPEZ-de-SILANES, Florencio; SHLEIFER, Andrei. Government Ownership of Banks. Harvard Institute of Economic Research, n. 1.890, 2000b. Discussion Paper.

LA PORTA, Rafael et al. Law and Finance. Journal of Political Economy, v. 106, n. 6, 1998. 
Legal Determinants of External Finance. The Journal of Finance, v. 52, n. 3, 1997.

Investor Protection and Corporate Governance. Journal of Financial Economics, n. 58, 2000a.

LAFER, Celso. JK e o Programa de Metas - processo de planejamento e sistema político no Brasil (1956-1961). Trad. Maria Victoria Benevides. Rio de Janeiro: FGV, 2002.

LEVINE, Ross. The Legal Environment, Banks, and Long-Run Economic Growth. Journal of Money, Credit and Banking, v. 30, n. 3, 1998.

MB ASSOCIADOS. Desafios e Oportunidades para o Mercado de Capitais Brasileiro. Estudos para o Desenvolvimento do Mercado de Capitais. São Paulo: Bovespa, 2000.

MILHAUPT, Curtis; PISTOR, Katharina. Law and Capitalism - What Corporate Crises Reveal About Legal Systems and Economic Development Around the World. Chigaco: Chicago Press, 2008.

MONTEIRO FILHA, Dulce. Aplicação dos Recursos Compulsórios pelo BNDES na Formação da Estrutura Setorial da Indústria - 1952-1989. Tese (Doutorado) - Instituto de Economia, Universidade Federal do Rio de Janeiro, 1994. NORTH, Douglas. Institutions, Institutional Change and Economic Performance. Cambridge: Cambridge University Press, 1990.

NOVAES, Ana. Intermediação Financeira, Bancos Estatais e o Mercado de Capitais: a experiência internacional. In: PINHEIRO, Armando Castelar; OLIVEIRA FILHO, Luiz Chrysostomo (Orgs.). Mercado de Capitais e Bancos Públicos - análise e experiências comparadas. Rio de Janeiro; São Paulo: Contra Capa; ANBID, 2007.

NUSDEO, Fábio. Bancos de Investimento. In: FRANCA, Rubens Limongi (Org.). Enciclopédia Saraiva do Direito, v. 10. São Paulo: Saraiva, 1977.

PISTOR, Katharina. Legal Ground Rules in Coordinated and Liberal Market Economies. Working Paper n.

30/2005, Columbia Law School, 2005.

POLANYI, Karl. La Economía como Actividad Institucionalizada. In: POLANYI, Karl. Comercio y Mercado en los Imperios Antiguos. Trad. Alberto Nicolás. Barcelona: Labor Universitaria, 1976.

RODRIK, Dani (Ed.). In Search of Prosperity - Analytic Narratives on Economic Growth. Nova Jersey: Princeton Press, 2001.

PRZEWORSKI, Adam. Institutions Matter? Government and Opposition, v. 39, 2004.

SABEL, Charles. Bootstrapping Development: Rethinking the Role of Public Intervention in Promoting Growth. In: Ética protestante e o espírito do capitalismo, 2004, Cornell. Paper... Cornell, 2004. Disponivel em:

$<$ http://www2.law.columbia.edu/sabel/papers.htm >.

SANTOS, Alvaro. The World Bank's Uses of the "Rule of Law" Promise. In: TRUBEK, David; SANTOS, Alvaro.

The New Law and Development - a Critical Appraisal. Nova Iorque: Cambridge, 2006.

SHLEIFER, Andrei; VISHNY, Robert. A Survey of Corporate Governance. The Journal of Finance, v. 52, n. $2,1997$. SCHAPIRO, Mario Gomes. Novos Parâmetros para a Intervenção do Estado na Economia: persistência e dinâmica na atuação do BNDES em uma economia baseada no conhecimento. 2009. Tese (Doutorado) - Faculdade de Direito, Universidade de São Paulo, São Paulo, 2009.

STALLINGS, Barbara; STUDART, Rogério. Finance for Development - Latin America in Comparative Perspective. Washington: Brookings Institution Press, 2006.

STIGLER, George. The Theory of Economic Regulation. The Bell Journal of Economics and Management Science, n. 2, 1971 .

TAMANAHA, Brian. An Analytical Map of Social Scientific Approaches to the Concept of Law. Oxford Journal of Legal Studies, v. 15, n. 4, 1995.

. The Primacy of Society and the Failures of Law and Development. In: INSTITUTE FOR LAW AND

DEVELOPMENT, 2009, Nagoya. Paper... Nagoya, 2009.

TREBILCOCK, Michael; PRADO, Mariana Mota. Path Dependence Theory, Economic Development and the Dynamics of Institutional Reform. University of Toronto Law Journal, 2009. Disponível em:

<http://papers.ssrn.com/sol3/papers.cfm?abstract_id=1415040>.

TRUBEK, David. The "Rule of Law" in Development Assistance: Past, Present, and Future. In: TRUBEK, David; SANTOS, Alvaro. The New Law and Development - a Critical Appraisal. Nova Iorque: Cambridge, 2006.

TRUBEK, David. Toward a Social Theory of Law: an Essay on the Study of Law and Development. Yale Law Journal, v. 82, n. 1, 1972.

TRUBEK, David; SANTOS, Alvaro. Introduction. Em TRUBEK, David; SANTOS, Alvaro. The New Law and Development - a Critical Appraisal. Nova York: Cambridge, 2006.

WILLIAMSON, Oliver. The Economic Institutions of Capitalism - Firm, Markets, Relational Contracting. Nova Iorque: Free Press, 1985.

YAZBEK, Otávio. Regulação do Mercado Financeiro e de Capitais. Rio de Janeiro: Elsevier, 2007.

ZYSMAN, John. Governments, Markets, and Growth - Financial Systems and the Politics of Industrial Change. Nova Iorque: Cornell Paperback, 1984. 
252 : REPENSANDO A RELAÇÃO ENTRE ESTADO, DIREITO E DESENVOLVIMENTO:

Mario Gomes Schapiro

Rua Rocha, 233, $8^{\circ}$ andar Bela Vista - 01330-000 São Paulo - SP - Brasil mario.schapirolafgv.br
PROFESSOR DOUTOR EM TEMPO INTEGRAL DA DIREITO GV MESTRE E DOUTOR EM DIREITO ECONÔMICO PELA FACULDADE de Direito da Universidade de São Paulo (FDUSP) 